\title{
THE FATE OF ERNST ISING AND THE FATE OF HIS MODEL*
}

\author{
T. Ising ${ }^{1}$, R. Folk ${ }^{2}$, R. Kenna ${ }^{3,1}$, B. Berche ${ }^{4,1}$, Yu. Holovatch ${ }^{5,1}$ \\ ${ }^{1} \mathbb{L}^{4}$ Collaboration \& Doctoral College for the Statistical Physics of Complex Systems, \\ Leipzig-Lorraine-Lviv-Coventry \\ 2 Institute for Theoretical Physics, Johannes Kepler University Linz, A-4040, Linz, Austria \\ ${ }^{3}$ Applied Mathematics Research Centre, Coventry University, Coventry, CV1 5FB, United Kingdom \\ ${ }^{4}$ Statistical Physics Group, Laboratoire de Physique et Chimie Théoriques, \\ Université de Lorraine, F-54506 Vandouvre-les-Nancy Cedex, France \\ ${ }^{5}$ Institute for Condensed Matter Physics, National Acad. Sci. of Ukraine, UA-79011, Lviv, Ukraine
}

(Received August 01, 2017)

\begin{abstract}
On this, the occasion of the 20th anniversary of the "Ising Lectures" in Lviv (Ukraine), we give some personal reflections about the famous model that was suggested by Wilhelm Lenz for ferromagnetism in 1920 and solved in one dimension by his PhD student, Ernst Ising, in 1924. That work of Lenz and Ising marked the start of a scientific direction that, over nearly 100 years, delivered extraordinary successes in explaining collective behaviour in a vast variety of systems, both within and beyond the natural sciences. The broadness of the appeal of the Ising model is reflected in the variety of talks presented at the Ising lectures (http://www.icmp.lviv.ua/ising/) over the past two decades but requires that we restrict this report to a small selection of topics. The paper starts with some personal memoirs of Thomas Ising (Ernst's son). We then discuss the history of the model, exact solutions, experimental realisations, and its extension to other fields.
\end{abstract}

Key words: Ising model, history of physics.

PACS number(s): 01.60. $+\mathrm{q}, 05.50 .+\mathrm{q}, 75.10 . \mathrm{Hk}$

\section{INTRODUCTION}

In seeking to explain a particular phenomenon in physics, namely the onset of ferromagnetism, Wilhelm Lenz proposed a model that was solved in one dimension by his PhD student, Ernst Ising in 1924. This event marked the start of a process that, over nearly 100 years, delivered tremendous and multiple successes in explaining collective behaviour in a vast variety of systems, including many beyond the natural sciences.

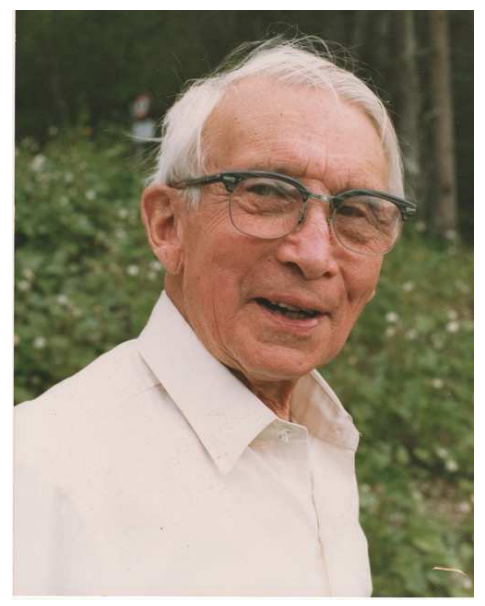

Fig. 1. Ernst (Ernest) Ising (May 10, 1900 in Cologne, Germany - May 11, 1998 in Peoria, USA). Photo taken in 1987.
When Ernst Ising started his work on the phenomenon of ferromagnetism, the nature of the microscopic, interatomic interactions was not yet understood. Indeed, it was not at all clear how a macroscopic magnetization could be generated by the interactions between elementary magnets. It was already known that magnetism is a quantum phenomenon but quantum theory was at a stage where the classical Bohr-Sommerfeld model was in disagreement with experiments. Ernst Ising succeeded in answering the question in the specific context of Lenz's suggestion for a linear chain. At the same time, Wolfgang Pauli, who was also at Lenz's institute, contributed to quantum mechanics by suggesting that the electron possesses a two valued non-classical magnetic moment. While these were important steps towards answering the above questions, the full picture had to wait for further new ideas.

Nowadays literature based on the Ising model is abundant and there are several good reviews that report the history of the model [1-3] and its applications in different fields of science [4-6]. About 800 papers on the Ising model are published every year $[3]^{(b)}$. It has found applications in a range of different circumstances such as tumor modelling [7], seismic-hazard assessment [8] and sonification of science (instead of visualization) [9]. Quite recently a universal simulator modelling spin models has been found [10]. Such broad impact of the Ising model is also reflected in the contributions to the "Ising lectures"

\footnotetext{
${ }^{*}$ The paper is a reprint of a chapter from the book Ising lectures in Lviv (1997-2017), edited by M. Krasnytska, R. de Regt, P. Sarkanych (Lviv, Institute for Condensed Matter Physics, 2017).
} 
- an annual workshop in Lviv that in 2017 celebrates its 20th anniversary [11], the occasion for which this paper is written. The broadness of the appeal of the Ising model requires that we restrict our report to a small selection of topics. Our paper is not meant to be comprehensive but rather reflects our own opinions on certain fields tightly related to the Ising model and its developments. In particular, in what follows we discuss the history of the model and its formulation as we now know it (Section III); exact solutions (Section IV); experimental realisations (Section V); and its extension to other fields (Section VI). We start with the personal memoirs of Thomas Ising (Ernst's son) in the next section.

\section{MY FATHER - ERNEST ISING}

My father was a wonderful person who was in love with life. He thoroughly enjoyed teaching: "I got some of the students in the front row wet with my experiment." He often stated that no class was complete unless his students had laughed with him.

When I first got to know him physics was something far away. He was only interested in keeping himself and our family alive in the middle of WWII. Starting with 1933, there were really only twelve very bad years for him.

He was born Ernst Ising, at the beginning of the 20th century on May 10th in Köln (or Cologne) near the cathedral. His mother, Thekla Loewe, came from a very successful Jewish merchant family in Duisburg. His father, Gustav, grew up in the small town of Rietberg in rural Westphalia, as a son of the local blacksmith. We do not know how or when Thekla and Gustav met, but Kaufhaus Loewe had quite a few male and female employees. Thekla, my grandmother, spoke of the table usually being set for about forty people. Gustav and his brother (?) Bernard ran a very successful upscale women's clothing store in Bochum until the Hitler years. By the time his sister, Charlotte (Lotte), was born in 1904, his parents had a wonderful home in a wealthier part of Bochum. Their home became a stopping point for many artistes of the period. It included a two-story stained glass stairwell by Johan Thorn Prikker. This unfortunately did not survive the war.

My father liked acting and had a stage in the basement where he and his friend, Heinz Wildhagen put on plays. Heinz spent his life as an actor and theater owner. Later the actor Willie Busch became my father's dictation coach.

After completing Gymnasium in 1918 he spent a few compulsory months as a soldier near the end of WWI. On the day that the war ended he was on a ladder hanging a banner. He said he looked around and everyone was gone! The war was over and they had all left.

In 1919 he started studying at the university in Göttingen majoring in math and physics. Later he was at the University in Bonn.

In graduate school at Hamburg University in 1922 he came under the tutelage of Professor Wilhelm Lenz, who suggested a doctoral thesis in ferromagnetism following up on his paper of 1920. The thesis was completed in 1924. One of his fellow students was Wolfgang Pauli. Also at this time his sister, Lotte, married Hermann Busch (Willie's brother) of the famous Busch family.

After receiving his $\mathrm{PhD}$ he went to work in the patent office of the AEG or the Allgemeine Elektrizitätsgesellschaft (General Electric) in Berlin. While he enjoyed the work, he knew that he preferred teaching. During this time he joined and hiked with members of the math and physics group where he met my mother. She had just received her Doctorate in Economics and was working for a professor at the university. In 1927 for a year Ernst worked as a teacher at the famous boarding school, Schule Schloss Salem, in Salem, near Lake Constance. He then went back to Berlin University in 1928 so he could begin studies on pedagogy and philosophy. Two years later, in 1930, he passed the state exams on higher education and they were married.

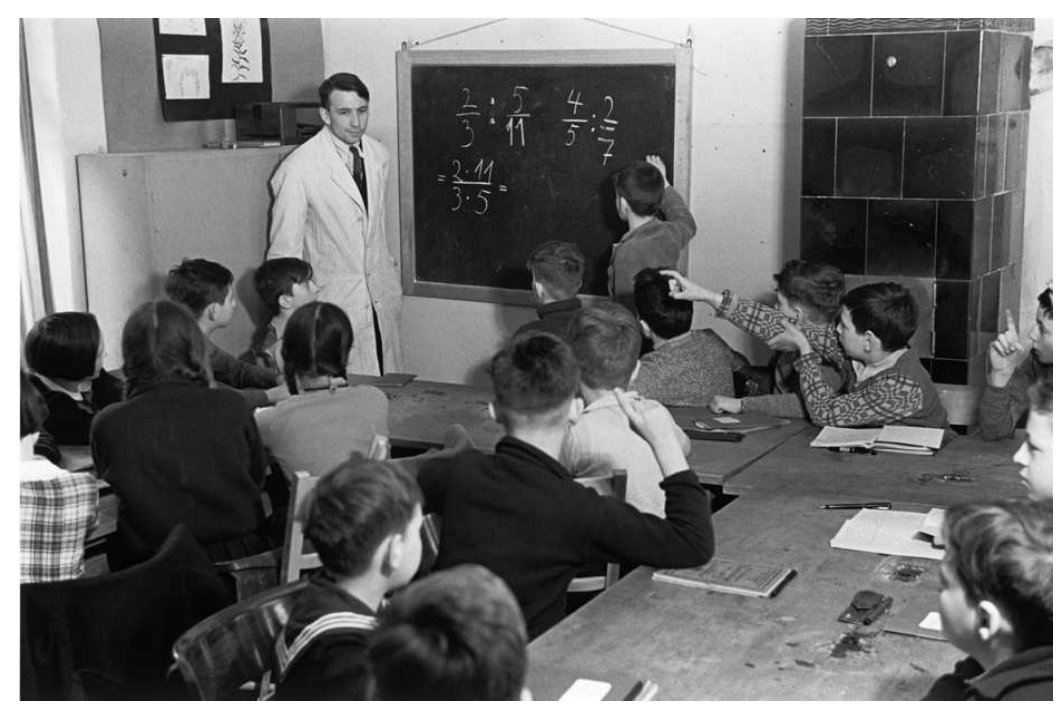

Fig. 2. Ernst Ising teaching one of his classes at Landschulheim Caputh. ${ }^{\circledR}$ Herbert Sonnenfeld, Judisches Museum Berlin. 
My parents moved to Strausberg where he had a teaching position and my mother could take the train to Berlin. This lasted for two wonderful years until April of 1933 when Jewish teachers were removed from their positions. This was the start of "12 years on a tightrope" as my mother described it.

There followed a year of searching, including a very temporary job at a school for emigrant children in Paris.

In 1934, he got a new job as a teacher for Jewish children at the Judishes Landschulheim in Caputh, a few miles from Potsdam (see Fig. 2). It was founded in 1931 by Gertrude Feiertag, who was a known progressive social educationalist. Next-door was the summerhouse of Albert Einstein. When Einstein permanently extended his USA visit in 1932, the school rented his house to be used as additional classrooms. This allowed the number of enrollees to increase due to the fact that Jewish children were being expelled from German public schools. Three years later my father took over the headmaster position. But as one survivor said, "the supposedly safe island threatened to go under the brown sea at any time, and the children and teachers knew that too".

While they were able to live near the campus by the relaxing Havel River, it was possible to take a daily swim and take out their Klepper foldboat, although the Nazi threat was constant. Once when they thought my father was about to have a nervous breakdown, my mother persuaded him to take a camping trip down the Danube River in their foldboat (see Fig. 3). At the end my father said it was much better than a sanitarium.

On 10 November 1938, the school was destroyed, as part of Kristalnacht, a program to get rid of the Jewish people in Germany. The children had been prepared and were led in four groups through the woods to transportation, home or safety. As one survivor put it, "it was just like in the 'Sound of Music'."

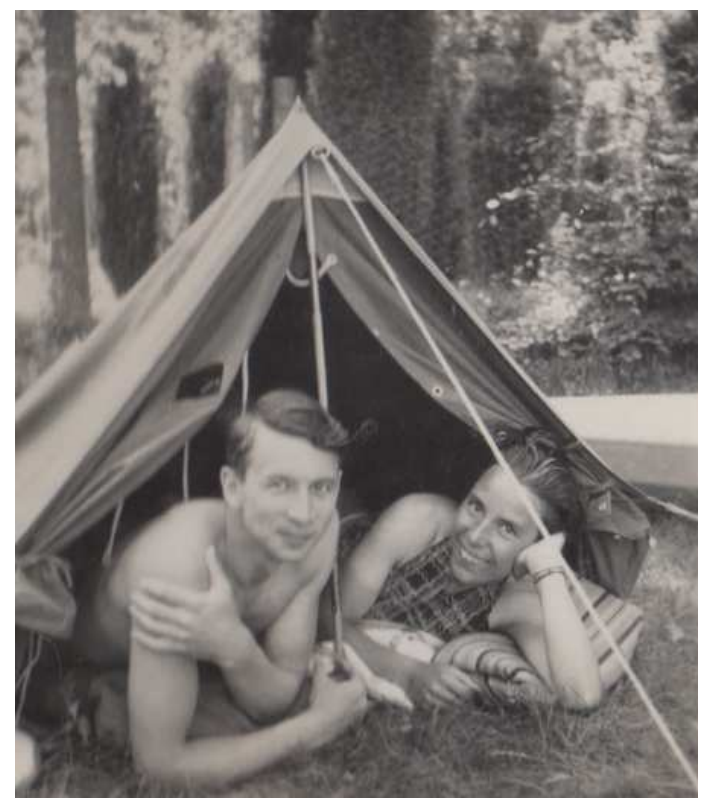

Fig. 3. Ernst Ising and his wife Jane (Johanna) Ehmer Ising during a camping trip down the Danube River in 1938.
On 27 January 1939, he was taken by the Gestapo and interrogated for four hours. He was only released after he promised that he and his wife would leave Germany. They gained entry to the closed borders of Luxembourg with the help of Dannie Heineman (of the Dannie Heineman physics prize) via his brother-in-law Hermann Busch and the Busch Quartet. The quartet always gave two extra private performances in Belgium, one for the Queen and one for Mr. Heineman. My parents had planned to emigrate to the United States, but at that time the quotas were full and they were forced to remain in Luxembourg where I was born. Dannie Heineman had arranged for some 100 German-Jewish families to occupy vacant hotels and to pay their room and board. The Germans invaded on my father's 40th birthday. After the Germans arrived Mr. Heineman made arrangements for one last payment of a six-month allowance.

After that they survived in Luxembourg during the whole war by my father doing mostly menial farm jobs. In between, there were ten months of teaching Jewish children denied public schools in Luxemburg City. Later there were several months of caring for sick and old Jews who had not yet been deported from the Cinqfontaines Monastery in northern Luxembourg. The Nazis had confiscated the Monastery and were using it as a deportation center to send the Jews to the camps. Near the end of the war, he was forced with other mixed married Jewish men to help dismantle rails of the Maginot line to be sent to the eastern front. He was left relatively unthreatened as he had both a non-Jewish wife and an "Aryan" son.

During this whole uncertain time they had acquired two used bicycles and we were able to escape on long bike rides through the countryside. Except for German control we were never in a war zone until the end. On September 10, 1944 allied soldiers arrived in Mersch and the horror was over. Later we escaped the Battle of the Bulge by only ten miles. Google indicates only 36 Jews survived in Luxemburg.

By 1946 we were able to take a month long vacation with my grandparents who had been lucky enough to survive the war safely in Basel, Switzerland. This included a five-day hike through the Alps with my 71-year-old grandmother (see Fig. 4).

It took over two years after the war ended for us to complete the paper work necessary to enter the US. In April 1947, we finally arrived in New York on the freighter "Lipscomb Lykes". That spring my father went to a physics convention in Boston to get a job. There he was asked for the first time if he was the "Ising" of the Ising Model.

During that summer my parents found work at the Tapawingo Farm Camp near Gouldsboro, PA. I was among other seven year olds who had Hanna Tillich as our housemother. Our English improved tremendously.

That fall my father started as a teacher at the State Teacher's College in Minot, North Dakota. He had to make a very radical change from teaching in a German high school nine years earlier to teaching in an American college in English. The next year he became a Physics Professor at Bradley University in Peoria, Illinois. His 
wife Jane (Americanized from Hanna) also became a teacher at the school. This was where they stayed. He retired in 1976. In 1953 we were granted our US cit- izenships. He officially became Ernest and my mother became Jane.

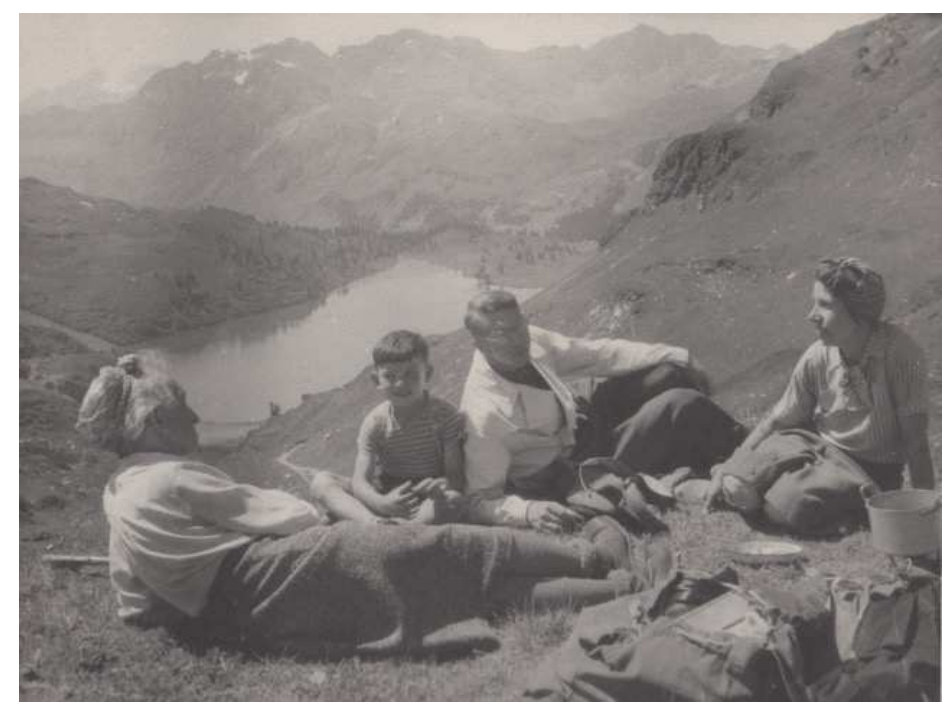

Fig. 4. Thekla Ising, Tom Ising, Ernst Ising and Johanna Ehmer Ising (from left to right) during their five-day hike through the Swiss Alps (1946).

My parents soon made many lasting friendships. Every summer we, or they, went on a significant trip, even driving up to Alaska one year. They also took several trips to Europe and many other parts of the world. On a lonely beach in Oregon the summer after my graduation, they happened to meet one of my physics professors. He exclaimed that he was writing a chapter on the Ising model in his new book.

My father passed away at home one day after his 98th birthday after only five days in hospice.

\section{FROM LENZ UMKLAPPMAGNETS VIA ISING'S CHAIN TO PAULI'S ZWEIDEUTIGKEIT}

The most successful elaboration of technique in statistical mechanics exists in connection with the Ising model. (G. H. Wannier 1966 [12])

Starting around 1925, a change occurred: With the work of Ising, statistical mechanics began to be used to describe the behaviour of many particles at once. (L. P. Kadanoff $2013)^{1}$

\section{A. Lenz paper from 1920}

Magnetism and especially ferromagnetism was a less understood phenomenon at the beginning of the 20th century. Pierre Curie discovered in 1895 that permanent magnets (ferromagnets) lose their magnetization if they are heated above a certain temperature $T_{C}$, now called Curie temperature [14]. Curie recognized that the behaviour near the critical point in fluids and magnets seems to be the same and introduced a kind of universality $^{2}$ by pointing to the "analogy between the way in which the intensity of magnetization of a magnetic body increases under the influence of temperature and the intensity of the field, and the way in which the density of a fluid increases under the influence of temperature and of the pressure."

Already in 1911 Niels Bohr and independently Hendrika Johanna van Leeuwen discovered that magnetism is not a classical but a quantum mechanical phenomenon. They proved" : "At any finite temperature, and in all finite applied electrical or thermal fields, the net magnetization of a collection of electrons in thermal equilibrium vanishes identically" [16,17]. Bohr postulated within his atomic model that the planetary-like electron orbiting

\footnotetext{
${ }^{1}$ In [13] Kadanoff cites together with Ising's 1925 paper Brush's review [1] who made a similar statement at the end of his paper.

2“Analogie entre la manière dont augmente l'intensité d'aimantation d'un corps magnétique sous l'influence de la température et l'intensité du champ, et la manière dont augmente la densité d'un fluide sous l'influence de la température et de la pression." [14]

${ }^{3}$ Bohr concluded in his thesis: a piece of metal in electric and thermal equilibrium will not possess any magnetic properties whatever due to the presence of free electrons (see [16], page 380).
} 
around the atomic nucleus has a quantized angular momentum and induces a magnetic moment. This condition allowed one to introduce atomic (molecular) magnetic moments, which could respond to an external field and to set up models for para- and diamagnetism. In gases the magnets, according to the freedom of the atoms or molecules, could be oriented in every direction. On the basis of such assumptions Curie's law (the dependence of the susceptibility $\chi$ with temperature $T$ as $\chi \sim c / T$ ) for paramagnets could be derived.

In 1920 Lenz questioned the assumption of free rotation of the elementary magnets in solids and suggested instead that they may change their direction just turning around by 180 degrees (Umklapp-Prozess) [18]. He then derived Curie's law. In the last paragraph of his short communication he suggested his two-state model also for ferromagnets in order to explain the appearance of a permanent magnetism at temperatures below $T_{C}$. He says: ${ }^{4}$ "If one assumes that in ferromagnetic bodies the potential energy of an atom (elementary magnet) with respect to its neighbors is different in the null position and in the $\pi$ position, then there arises a natural directedness of the atom corresponding to the crystal state, and hence a spontaneous magnetization." (translation from $[2]^{(a)}$ ).

In Weiss's domain model for ferromagnetism [19] it is the reaction of already ordered domains to a magnetic field which leads to the Curie-Weiss susceptibility $\chi \sim c /\left(T-T_{C}\right)$, whereas in Lenz's suggestion it is an unknown kind of non-magnetic interaction between the two directions of the elementary magnets.

After Lenz took up the post of Chair of Theoretical Physics at the University of Hamburg he was able to lead a group of physicists and young students to work on the project he suggested in his short paper [20]. Einstein considered Lenz's papers on magnetism, although published incompletely, as "extremely important" ( [20] p. 93). The first to become involved in this project was Ernst Ising, who was already a student in Hamburg when Lenz became full professor. In 1922 Lenz proposed the problem outlined in his 1920 paper for Ising's thesis, Beitrag zur Theorie des Ferro- und Paramagnetismus [21]. ${ }^{5}$
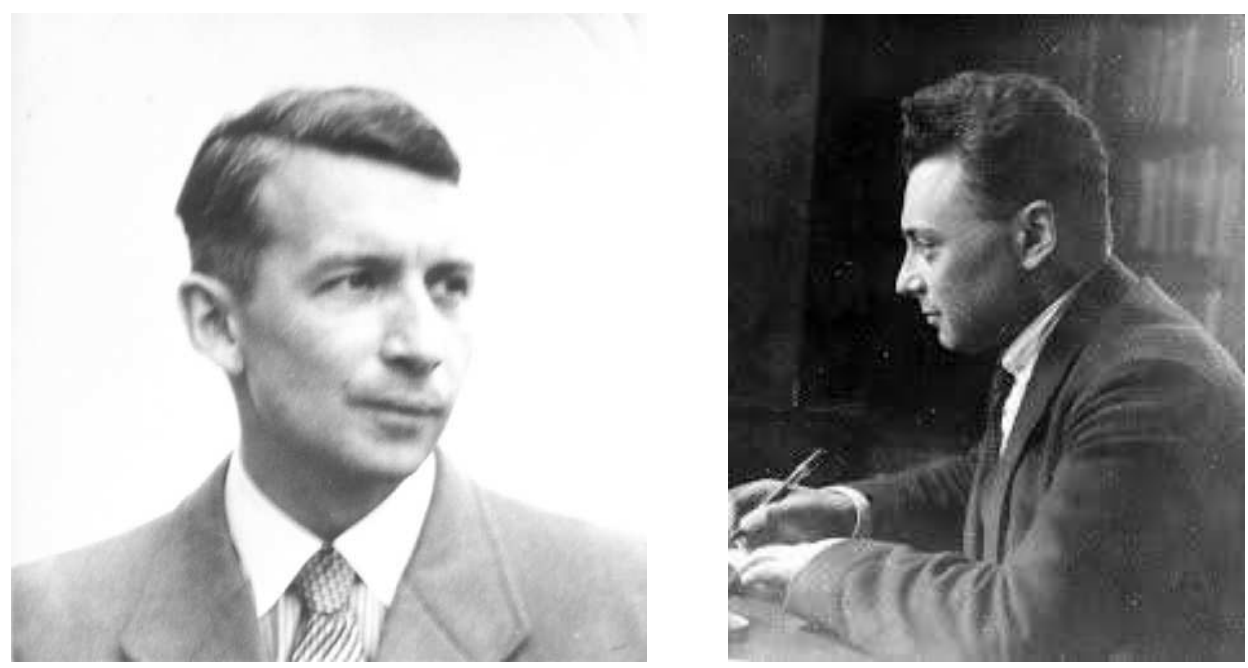

Fig. 5. Ernst Ising and Wolfgang Pauli during the time in Hamburg about 1925.

In May of the same year (1922) Lenz managed to obtain Wolfgang Pauli as an assistant. ${ }^{6}$ He was of the same age as Ising but already an internationally well-known physicist. He came from Göttingen where he worked with Max Born [34] on problems with the Bohr-Sommerfeld's atomic model and remained in Hamburg where he submitted his Habilitation on 17 January 1924. He stayed in Hamburg until March 1928 and moved to Zürich when he got a Chair at the Technical University. In 1923, during his stay at the institute of Lenz, he visited for almost one year Bohr's institute at Copenhagen. During this time Ising replaced Pauli until his return at the end of September 1923 (see Fig. 5).

\section{B. Ising's thesis and his 1925 publication}

The goal of Ising's task assigned by Lenz was to explain the appearance of a ferromagnetic state in a three dimensional (3D) solid. In fact this job was a twofold one: First he had to set up the model for the interaction of

\footnotetext{
4"Nimmt man an, daß im ferromagnetischen Körper die potentielle Energie eines Atoms (Elementarmagnets) gegenüber seinen Nachbarn in der Nullage eine andere ist als in der $\pi$ Lage, so entsteht eine natürliche zum Kristallzustand gehörige Gerichtetheit der Atome und daher spontane Magnetisierung."

${ }^{5}$ Contribution to the theory of the ferro- and paramagnetism.

${ }^{6}$ In fact his title was "wissenschaftlicher Hilfsarbeiter".
} 
the elementary magnetic units, which prefer alignment, a problem which belonged to the new and undeveloped quantum mechanics. Second he then had to calculate analytically the macroscopic magnetization with the methods of statistical mechanics.

Both tasks were far too big to be solved in a thesis as the development of quantum mechanics and statistical physics later showed. The first problem one could say was answered in 1928 by Heisenberg [22] after the theory of quantum mechanics proceeded far enough and the second in 1941 by Onsager [23] in 2D after special properties of the model had been clarified by Kramers and Wannier and new methods of calculating a partition function had been found $[24,25]$. The 3D problem remained analytically unsolved until now (see chapter IV for more details).

Therefore Ising had to restrict himself for the first problem to arguments for the model and for the second problem to reductions and approximations. In order to come along with the first problem he refers in the introduction to the paper of E. A. Ewing [26], "where it was shown experimentally and theoretically, that ferro- magnetism is caused by a mutual interaction of the elementary magnets." But the interaction is not thought to be the well known interaction between dipoles. In fact "no statement on the nature of this force, which might be of electrical nature [27] can be made, but it is assumed that it decays rapidly with the distance." It is interesting that these references are missing from his 1925 publication. So Ising concludes a nearest neighbor interaction is sufficient. He further points out that this is "in crass disagreement" with the hypothesis of a molecular field. We now know that the critical behaviour of systems with phase transitions is described by mean field in dimensions high enough otherwise it is an approximation or misleading as in the $1 \mathrm{D}$ case here.

In order to attack the second task Ising restricted himself to the $1 \mathrm{D}$ case - the famous Ising chain. ${ }^{7}$ In the thesis the configurations on the chain are displayed as vectors parallel or antiparallel to the direction of the chain. This presentation in the publication is replaced by the short notation plus and minus restricting to orientations only parallel or antiparallel to the direction of the chain.

$$
\begin{gathered}
\frac{\partial}{\partial \alpha} \log Z \text { wegen } n \geqslant 1 \text { vernachlässigen kann, so findet man gemäß Gl. (6) } \\
\qquad=\mathrm{m} \cdot n \cdot \frac{\operatorname{Gin} \alpha}{\sqrt{\operatorname{Gin}^{2} \alpha+e^{-\frac{2 \varepsilon}{k T}}}} .
\end{gathered}
$$

Diese Funktion verschwindet für $\mathfrak{S}=0$, d. h. $\alpha=0$ : wir finden

Fig. 6. Ernst Ising's result for the magnetization of the chain [28].

The calculation follows the standard methods of equilibrium statistical mechanics. Namely counting the configuration of different energy in order to obtain the partition function and in a next step the mean magnetization $\mathcal{J}$

$$
\mathcal{J}=m \cdot n \cdot \frac{\sinh \alpha}{\sqrt{\sinh ^{2} \alpha+e^{-\frac{2 \epsilon}{k T}}}}, \quad \alpha=\frac{m H}{k T}
$$

where $m$ is the elementary magnetic moment, $H$ is the external field, $T$ the temperature, $k$ the Boltzmann constant and $n$ the number of elements of the chain (see
Fig. 6). Thus in zero field no macroscopic magnetization arises at finite temperature.

Ising tried to generalize the model to higher dimensions ${ }^{8}$ : "It is imaginable that a spatial model, in which all elements that in some way are neighbors affect each other, brings with it the necessary stability to prevent the magnetization intensity to vanish with $H$. However, in that case the calculations do not seem to be feasible; at any rate, so far it has not been possible to sort and count the appropriate arrangement possibilities." (translation from $\left.[2]^{(a)}\right)$. Indeed this is not possible (so far) and one had to look for approximations. He

\footnotetext{
${ }^{7}$ This problem is reconsidered by Kramers and Wannier in paper [24] in section 2 as an easy introduction to their new method. In section 3 they explain: "The reduction of the linear chain problem can be described in a qualitative way as follows. It is possible to build up a chain by repeating constantly one and the same operation, namely adding another spin beyond the one just placed previously" (emphasis by the authors of this paper) They explain, that the successful mathematical treatment is based on one hand on the fact that no physical change takes place by this procedure, if the chain is very long and on the other hand that the state of the last added spin depends only upon the state of the predecessor.

${ }^{8}$ "Es ist ja denkbar, dass ein räumliches Modell, bei dem alle irgendwie benachbarten Elemente auf einander wirken, die nötige Stabilität mit sich bringt, um zu verhindern, dass die Magnetisierungsintensität mit H verschwindet. Doch es scheint in diesem Fall die Rechnung nicht durchführbar zu sein; jedenfalls ist es bisher nicht gelungen, die Anordnungsmöglichkeiten geeignet zu sortieren und abzuzählen."
} 
considered different kinds of arranging 1D chains. In the publication (section 3. "The spatial model") he assumed the special limit where $n_{1}$ identical chains are spacially arranged. He argues that differences in the configuration of the interacting chains are energetically unfavorable. Therefore the result is

$$
\mathcal{J}=m \cdot n \cdot n_{1} \cdot \frac{\sinh n_{1} \alpha}{\sqrt{\sinh ^{2} n_{1} \alpha+e^{-\frac{2 n_{1} \epsilon}{k T}}}}
$$

and once again (although not surprising due to the approximation) one does not find a finite magnetization in zero magnetic field.

Based on these results in the thesis he concludes: "So, if we do not assume, as P. Weiss did, that also quite distant elements exert an influence on each other - and this seems to us not to be allowed under any circumstances - we do not succeed in explaining ferromagnetism from our assumptions. It is to be expected that this assertion also holds true for a spatial model in which only elements in the nearby environment interact with each other" (translation from [2] ${ }^{(a)}$ ).

Ising finished his thesis in 1924 and published in 1925 a short paper [28] with his results. There is not much known about the contact between Ising and Pauli, but Brush [1] reports a letter from Ising to him where he stated "... I discussed the result of my paper widely with Professor Lenz and with Dr. Wolfgang Pauli, who at that time was teaching in Hamburg. There was some disappointment that the linear model did not show the expected ferromagnetic properties...". No further communication is reported apart from a letter from Pauli to Ising found by Sigmund Kobe $[3]^{(d)}$, where Pauli informed Ising about his fate and that of other colleagues in Hamburg after Ising left the institute and which were also known by Ising.

\section{Pauli's struggle with the Bohr-Sommerfeld model of the atom}

The Bohr-Sommerfeld model of atoms was only partly successful in explaining the experiments. It failed in cases where more than one electron was present in the shell, but even in the case of one electron discrepancies appeared. The situation in the year 1923 is explained by Landé in a short note [29]. He mentioned that ${ }^{10}$ "It turns out that in systems with more than one electron not even the quantum theoretical stationary states and their adiabatic changes are mechanically calculable." He notes as an example the helium atom and adds: "The second particularly drastic example for the failure of the mechanical basic principles also in stationary quantum states illustrates the multiplet structure and especially the anomalous Zeeman effect ...".

After his stay in Kopenhagen Pauli gave his "Antrittsvorlesung" where he described the situation of the mechanical atomic theory. He states: ${ }^{12}$ "The contents of this lecture appeared very unsatisfactory to me, since the problem of the closing of the electronic shells had been clarified no further. The only thing that was clear was that a closer relation of this problem to the theory of multiplet structure must exist." For another description of the desperate situation by 1924 see [30, p. 125].

Another severe problem was the understanding of the periodic system although Bohr constructed with the help of an additional principle ("Aufbauprinzip") the structure of the shells in the classical atomic model. Pauli tried to connect all these problems and solve them with a new principle by postulating a fourth quantum number for the electron and formulating his exclusion principle (the name was given to it by Paul Dirac [32, p. 59]) for the electrons. He published those ideas in $1925\left[33\right.$, p. 385 ${ }^{(a)}$ and $[33, \text { p. } 765]^{(b)}$ where he concludes: ${ }^{13}$ "According to this point of view the doublet structure of the alkali spectra, as also the piercing of the Larmor theorem, comes about by a peculiar, classically not describable kind of two-valuedness of the quantum mechanical properties of the valence electron." (translation from [34, p. 107]) The expression "classically not describable" (nonclassic ) was certified by later development since Bohr was able to show that the spin could not be measured by classically describable experiments [31].

The dramatic story of Pauli's struggle to increase the quantity of quantum numbers from three to four is described by A. I. Miller [32] (see also [35-37]). Immediately afterwards G. Uhlenbeck and S. A. Goudsmit introduced

\footnotetext{
9"Wenn wir also nicht annehmen, wie dies P. Weiss tut, dass auch recht entfernte Elemente einen Einfluss aufeinander ausüben - und das scheint uns auf keinen Fall zulässig zu sein - so gelangen wir bei unseren Annahmen nicht zu einer Erklärung des Ferromagnetismus. Es ist zu vermuten, dass diese Aussage auch für ein räumliches Modell zutrifft, bei dem nur Elemente der näheren Umgebung aufeinander wirken."

10"Es zeigt sich nämlich, daß bei Systemen aus mehreren Elektronen nicht einmal die quantentheoretisch stationären Zustände und ihre adiabatischen änderungen mechanisch berechenbar sind."

11“Das zweite besonders drastische Beispiel für das Versagen der mechanischen Grundprinzipien auch in stationären Quantenzuständen gibt die Multiplettstruktur und speziell der anomale Zeemanneffekt ..."

12"Der Inhalt dieser Vorlesung schien mir sehr unbefriedigend, da das Problem des Abschlusses der Elektronenschalen noch nicht weiter geklärt war. Das einzige was klar war, war, daß eine engere Beziehung zwischen diesem Problem und der Theorie der Multiplettstruktur bestehen muß."

13"Die Dublettstruktur der Alkalispektren sowie die Durchbrechung des Larmortheorems kommt gemäß diesem Standpunkt durch eine eigentümliche, klassisch nicht beschreibbare Art von Zweideutigkeit der quantentheoretischen Eigenschaften des Leuchtelektrons zustande."
} 
for this two-valuedness the concept of the spin for the electron [38]. Already in 1921 A. K. Compton discussed the possibility that the electron possesses a magnetic moment as a result of its spinning motion. A similar idea was formulated by Ralph Kronig but never published.

After Ising had published his negative result it remained open in the physical community if the higher dimensional cases would lead to spontaneous magnetization or not. Pauli communicated about this question with Heisenberg (see [39, p. 129ff.]) and Heisenberg expressed his belief that if the number of the nearest neighbors (i.e. the dimension) is high enough one would succeed finding ferromagnetism.

\section{The formulation of the Hamiltonian for the Ising model}

The quantum mechanical foundation of the interaction which might lead to ferromagnetism was introduced in 1928 by Heisenberg [22]. It is known as the exchange interaction and is due to the overlap of the wave function of neighboring atoms obeying the exclusion principle. In this way the magnetic moments due to the spin of the electron define the interaction. If the spins are parallel the electrostatic energy is changed so that this configuration is more favorable. He concluded in his paper ${ }^{14}$ : "(1) The crystal lattice has to be such, that each atom has at least 8 neighbors. (2) The main quantum number of the electrons which are responsible for the magnetism has to be $n \geq 3$."
In the year 1930 Pauli was invited to the Solvay conference His invited talk [40] gave a review of the status of the theory concerning magnetism and its quantum mechanical nature (for a short content of his talk see [34, p. 220 ff.]) Especially interesting for ferromagnetism is Section 5 of [40]. Here for the first time it is mentioned that the phase transition could depend on dimensionality. He also mentions Ising's work in connection with Heisenberg's work and its result for the magnetic moment in molecular field theory

$$
\mathcal{M}=N \mu_{0}\left[1-C\left(\frac{T}{\Theta}\right)^{\frac{3}{2}}\right]
$$

He states: ${ }^{15}$ "There is in fact a very close relationship between the problem of Ising and the one we have just treated" [40, p. 209]. Pauli's critical appreciation of Ising's model was: ${ }^{16}$ "In Ising's calculation developed from the point of view of the old quantum mechanics, the components of $\sigma_{i}$ that are perpendicular to the field are considered to be zero, whereas in the new quantum theory these components do not commute with the components in the direction of the field." (translation from $\left[2\right.$, p. 291] ${ }^{(a)}$ slightly corrected) But Pauli immediately suspects for the classical variant: ${ }^{17}$ "Irrespective of this difference, it is quite likely that an extension of the theory of Ising to the case of a lattice of three dimensions would yield ferromagnetism even from the classical point of view" (emphasis by the authors of this paper).

parallèlement ou en sens opposés. On peut dire que l'énergie, ou la fonction d'Hamilton, est dans ce cas

$$
\mathscr{H}=-\mathbf{A} \sum_{k}\left(\sigma_{k}, \sigma_{k+1}\right)
$$

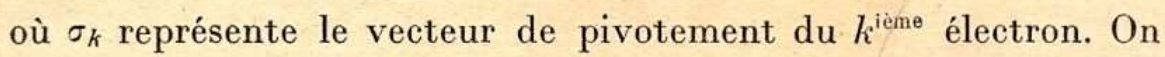
a $\left(\sigma, \sigma_{k+1}\right)= \pm$ I suivant que les pivotements sont parallèles ou opposés. Ising n'a rien trouvé, dans les propriétés de ce modèle, qui corresponde au ferromagnétisme, mais une dépendance entre

Fig. 7. Part of page 210 of Pauli's contribution to the Solvay conference [40], where he presented the Ising model in the form as it is known nowadays.

\footnotetext{
14“(1) Das Kristallgitter muß von solcher Art sein, daß jedes Atom mindestens 8 Nachbarn hat. (2) Die Hauptquantenzahl der für den Magnetismus verantwortlichen Elektronen muß $n \geq 3$ sein."

${ }^{15}$ "Ce résultat est interéssant en liason avec la discussion d'un modèle semi-classique proposé par Ising."

16"Dans le calcul d'Ising, développé au point de vue de l'ancienne théorie des quanta, les composantes des $\sigma_{i}$ perpendiculaires à la direction du champ sont considérées comme nulles, tandis que dans la nouvelle mécanique cette composante n'est pas commutable avec celle qui correspond à la direction du champ."

17" Malgré cette différence, il est très vraisemblable qu'une extension de la théorie d'Ising au cas d'un réseau à trois dimensions donnerait du ferromagnétisme même au point de vue classique."
} 
Thus it was Pauli himself who introduced the modern notation for the Ising model [40, p. 210], see Fig. 7,

$$
H=-A \sum_{k}\left(\sigma_{k}, \sigma_{k+1}\right)
$$

where $A$ gives the strength of the interaction of the spins on the chain position $k$. Pauli pointed to the difference of the properties of a quantum mechanical spin $\sigma_{k}$ and called the "spin" appearing in the Ising model a semiclassical spin.

This compact formulation of the Ising model includes already all the aspects important for the following development: (1) the whole system is described as an interacting many-particle system, (2) these individual particles produce a specific collective behaviour leading eventually to phase transitions. The formulation also separates the aspects, the strength $A$ of interaction of the interacting units, and the properties of the units $\sigma_{i}$ themselves. $A$ is dependent on the ferromagnet considered whereas the units are the same for the whole group of ferromagnets. This reflects the important concept of universality, at least for ferromagnets, already introduced in 1908 by Pierre Curie [15] within mean field theory and comprising phase transitions in liquids and magnets. Future developments like scaling theory and renormalization group theory show that this universality concept goes beyond mean field theory and the Ising model in three dimensions. Rather it describes the critical behaviour of a whole universality class containing liquids, magnets and other physical systems of same dimension, symmetry and type of short ranged interaction.

\section{E. Comments on Ising's result}

The usual explanation for the negative result for permanent magnetization at finite temperature in the $1 \mathrm{D}$ case points to the free energy. It consists of two parts, the internal energy and a negative entropic term. This entropic term favors disorder in the $1 \mathrm{D}$ case against macroscopic alignment. Another question was if some kind of long range interaction could change the result. Already from the Curie-Weiss model it was known that taking into account the interaction of all the spins by an effective field a phase transition came about even in the 1D case. However an interaction between two positions in the chain $i, j$ with a decay according to a power law like $1 /|i-j|^{1+\alpha}$ leads to a phase transition for a sufficient weak decay, $\alpha<1$ [41] (see also [42]).

Ising had to struggle with the configurations of the chain. A much more elegant way, used mainly in textbooks, is to calculate the partition function with the method of transfer matrices developed by Kramers and Wannier [24, 25].

Pauli's criticism that in fact quantum mechanics formulates a model where the units are non-classical was taken up in the 1960's. It turned out that (a) there are physical examples for which such a model might be applicable and (b) numerical solutions of the problem could be obtained [43]. It also opened the new field of quantum phase transitions.

\section{MORE ON EXACT SOLUTIONS}

In the 1920's, the dominant theory for magnetism was that of Pierre Weiss [19]. This was based on the suggestion that ferromagnets comprise domains of parallelaligned micromagnets. Each micromagnet within a domain is supposed to experience an effective magnetic field (the Weiss mean field) coming from its neighboring magnetic moments. Each magnetic domain is then randomly aligned, up to preferences induced by crystallographic symmetries. Alternatives to Weiss's formulation include the Bragg-Williams approximation [48] as well as Bethelattice models [49]. The free energy coming from such mean-field approaches is

$$
f(\beta, h)=\frac{q J m^{2}}{2}-\frac{1}{\beta} \ln [2 \cosh h+J \beta q m],
$$

where $\beta=1 / k T, k$ is the Boltzmann factor, $T$ is the temperature, $h=\beta H$ where $H$ is the strength of an external field, $q$ is the coordination number (the number of the nearest neighbours of a given site, e.g., $q=2 d$ for a regular lattice of dimensionality $d$ ), $J$ is the strength of the inter-site couplings and $m$ is the mean-field magnetization. The model manifests a phase transition at $h=0$ characterised by non-vanishing and vanishing values of $m$ on either side of a critical temperature $T_{c}=q \mathrm{~J} / \mathrm{k}$. It also exhibits discontinuity in the specific heat (the second temperature derivative of the free energy) there.

Following the discovery of the specific-heat anomaly of liquid helium at temperatures of around $2.19 \mathrm{~K}$, Ehrenfest introduced a classification system for phase transitions [50]. He christened the anomaly the "lambda point" because of the shape of the experimentally obtained specific-heat curve. He argued that the lambda point is a phase transition, even though it was dissimilar to other known phase transitions in that it did not feature a latent heat or change in volume. Ehrenfest had interpreted the lambda point as a finite discontinuity and he proposed to classify such phase transitions as first- or second-order depending on whether such a discontinuity was in the first or second derivative of the free energy. For a recent review of Ehrenfest's scheme and a translation of his original paper [50], see [51]. Thus the mean-field model predicts a second-order phase transition in the original Ehrenfest sense. Moreover this prediction holds for all dimensionalities.

In [28], Ising explicitly highlights the difference between his and Weiss's treatment in that only short-range, nearest-neighbouring interactions are taken into account and the orientation of each micromagnet is restricted to only two possibilities. The solution for the free energy is 


$$
f(\beta, h)=-\frac{1}{\beta} \ln \left[e^{\beta J} \cosh \beta h+\sqrt{e^{2 \beta J}(\sinh \beta h)^{2}+e^{-2 \beta J}}\right]
$$

and the various thermodynamic functions are easily derived by appropriate differentiation. As we have seen, unlike mean-field theory, the model does not exhibit spontaneous magnetisation.

In 1936, however, Rudolf Peierls showed that the model does manifest ferromagnetism in two dimensions [44] and this problem was investigated by Hendrik Kramers and Gregory Wannier in 1941 [24]. They write in the introduction to their paper: "The problem has a mechanical and a statistical aspect. On the mechanical side we wish to improve our understanding of the responsible coupling forces. On the statistical side we wish to derive with certainty the thermal properties from a reasonable accurate mechanical model. Both aspects have received extensive attention. Quantum theory has explained satisfactorily the origin and nature of the coupling forces. There are also several theories available which explain in terms of them the thermal behaviour of ferromagnets. Not one, however, applies just straight statistics to the mechanical data. Generally some simplifying assumption is introduced to facilitate the evaluation of the partition function. It follows that the results obtained are not necessarily a consequence of the mechanical model, but may well be due to the statistical approximation." In their paper they then introduced the transfer matrix concept and related the free energy of the Ising model for high temperature to a conjugate Ising model at low temperature. By using this relation they were able to calculate the transition temperature of the 2D Ising model. They also developed the transfer matrix method and demonstrated it by re-deriving Ising's results for the one dimensional chain. By their method they reduced the calculation of the partition function to finding the largest eigenvalue of a two by two matrix. For the two dimensional Ising model the matrix turns out to be a square matrix of infinite dimension and Kramers and Wannier could calculate the finite transition temperature $T_{c}$. They showed that the partition function for the infinite system is related to the largest eigenvalue of the matrix. They also discovered a symmetry in the twodimensional model in that its free energy at low temperature is related to that at high temperature. The exact location for the critical point of the model with squarelattice geometry is then determined as the point which is invariant under this self-duality transformation. It is given by $k T_{c} / J=2 / \ln (1+\sqrt{2}) \approx 2.269185$. By way of comparison mean-field model theory gives $k T_{c} / J=4$ for $d=2$ and the Bethe approximation gives 2.88.

Onsager solved the model for the square lattice in the absence of an external field (i.e., with $h=0$ ) and famously announced his result at the end of the talk by Wannier at the February 1942 meeting of the New York academy of Sciences. He published the result in 1944 in [23]. The free energy of the infinite system in the absence of an external field is

$$
-\beta f=\ln 2+\frac{1}{8 \pi^{2}} \int_{0}^{2 \pi} d \theta_{1} \int_{0}^{2 \pi} d \theta_{2} \ln \left[\cosh \left(2 \beta J_{1}\right) \cosh \left(2 \beta J_{2}\right)-\sinh \left(2 \beta J_{1}\right) \cos \theta_{1}-\sinh \left(2 \beta J_{2}\right) \cos \theta_{2}\right]
$$

in which $J_{1}$ and $J_{2}$ are the coupling constants between spins in the two different directions.

This was a milestone achievement in the history of the Ising model in that it was the first exact result for the model with a finite-temperature phase transition and proved that these can be captured by statistical mechanics. Strictly speaking, the phase transition was not of the Ehrenfest type - it has a logarithmic divergence instead of a discontinuity in the specific heat [25]. Nowadays we consider Ehrenfest's classification scheme as extended to include phase transitions with a divergence as well as those with a discontinuity. The significance of Onsager's achievement is reflected in the comment by Wolfgang Pauli to Hendrik Casimir who had inquired about developments in theoretical physics during the second World War: "nothing much of interest has happened except for Onsager's exact solution of the Two-Dimensional Ising Model" [52]. Onsager's solution was simplified by Bruria
Kaufman in 1949 [53] and Kaufman and Onsager determined correlation functions in [54].

Onsager made another important announcement at the end of the talk by László Tisza at Cornell University in 1948 [52]. This time he stated that Kaufman and he had derived the spontaneous magnetisation of the two-dimensional Ising model and he wrote the formula on the blackboard. This was important because the non-vanishing of the magnetisation on one side of the transition $\left(T<T_{c}\right)$ and its vanishing on the other $\left(T>T_{c}\right)$ established the phenomenon as a genuine phase transition. Onsager repeated the claim in May 1949 at a conference of the International Union of Physics in Florence after the talk by George Stanley Rushbrooke [52] but he and Kaufman did not publish the derivation; the first to do so was Chen-Ning Yang in 1952 [55]. Rodney Baxter recently reviewed how the Kaufman-Onsager calculation was developed and added a draft paper giv- 
ing their result [56]. That result is that the spontaneous magnetisation behaves near the critical point as $\left(T_{c}-T\right)^{\beta}$ with $\beta=1 / 8$. This is different to the mean-field result which is that $\beta=1 / 2$. A deviation from mean field exponents was already observed by Verschaffelt [47] in liquids around 1900 and corroborated by further experimental material in different systems. With Kaufman in 1949 Onsager also derived the correlation function at the critical point, and showed that it decays as $1 / r^{1 / 4}$ [54]. In 1965, Alexander Patashinski and Valery Pokrovsky gave the correlation-function exponential decay away from the critical point [57]. The two-dimensional model has still not been solved in the presence of an external field, apart from the $c$-theorem approach of Zamolodchikov [58] using perturbed conformal field theories [59] where the model turns out to be an example of integrable massive field theory.

In $[2]^{(a)}$, Niss discusses the early years of the Ising model within the context of quantum- and statisticalmechanical models of magnetism. From the late 1940's and in the 1950's the model was not believed to provide a good description of magnetic materials due to its lack of physical realism $[2]^{(b)}$. The restriction of the interatomic forces to nearest-neighbouring sites and the further restriction of spins of the Ising model to only two orientations were considered to distance the model from the reality wherein the electron spin can have any direction in three-dimensional space [60]. It was thought that, at best, the Ising model may physically represent anisotropic magnetic materials in which the two spin directions were allowed or binary alloys with spins of each orientation corresponding to one of the two types of atom in the compound. It was also considered a model for lattice gas, in which the presence or absence of a molecule at a point in space was represented by one of the two spin orientations. But as a model of a magnet, it was considered deficient and its interest in this regard was instead as a simplified model of phase transitions in general that has the advantage of being mathematically tractable $[2]^{(b)}$.

The group around Cyril Domb in King's College London did, however, appreciate the physical importance of the Ising model $[2]^{(b)}$. They worked on different types of 2D lattices, using geometries other than squares, and pioneered series-expansion approaches, a strategy also employed by the Rushbrooke group at the University of Newcastle. They gained the crucial insight that the critical exponents describing the phase transition depend strongly on the dimensionality of the system and less so on the geometry of the lattices. This would later be explained by the notion of universality (see section VA). The role of dimensionality in the Ising model was therefore quite different to that in mean-field theories, where it is unimportant for the critical exponents $[2]^{(b)}$.

Comparisons between series expansions and the exact solution in two dimensions lent confidence that the approximate approach may be applied to the threedimensional version as well as to other models. Indeed, and as discussed in $[2]^{(c)}$, the Onsager solution to the two-dimensional Ising model frequently played (and continues to play) a role analogous to that traditionally played by experiment in that hypotheses were tested against it. This includes the scaling relations between the various critical exponents describing continuous phase transitions. These establish that the critical exponents are not all independent. The development of the scaling relations by figures such as John Essam, Michael Fisher and Benjamin Widom (and the related inequalities derived by Robert Griffiths, Brian Josephson, Rushbrooke and others) were pivotal to the development of more general theories of critical phenomena (for a review, see e.g., [61]). They helped pave the way for Widom's hypothesis that the singular part of the free energy is a homogeneous function of its arguments. The explanation for Widom's form was, in turn, given by Leo Kadanoff who ascribed the singularity in the free energy to the occurrence of large-scale fluctuations in the system as the critical point is approached. These fluctuations cause the correlation length to diverge and the relation between temperature, field and length scales, a concept captured by Kadanoff's block-spin formulation and ultimately by Ken Wilson's renormalisation group. The renormalisation group forms the foundation stone on which the entire modern theory of critical phenomena is built and which is of fundamental importance not just for statistical physics but also for high-energy physics and any physical system which can be viewed at different distance scales. This also explained the crucial concept of universality, to use the term coined by Kadanoff in 1971. This means that critical exponents are independent of many details of the Hamiltonian, and are functions instead of the system dimensionality, its internal symmetries and the range of interaction between its constituent entities (spins) (see Section V for experimental verifications).

The three-dimensional Ising model has proved to be a far tougher problem than its lower-dimensional counterparts and a solution remains elusive, even in the absence of an external field. It has a status in statistical physics similar to that which Fermat's last theorem occupied in mathematics until the proof of the latter by Andrew Wiles in 1994; the problem is easily formulated but hard to solve. Already in 1945 Wannier hoped that an analytic solution was imminent and both Onsager and Wolfgang Pauli are believed to have attempted it in the 1950s [2] ${ }^{(b)}$. Other notable names worked on a solution $[62,63]$ "and in the 1950 s physicists gradually concluded that a solution was not within reach" $[2]^{(b)}$.

In 1986, Anders Rosengren reported an attempt to generalise combinatorial considerations of the $2 \mathrm{D}$ nearest-neighbour model to the three-dimensional simple cubic case. This led to the "Rosengren conjecture" that the critical temperature for the 3D case is given by $\tanh \left(J / k T_{c}\right)=(\sqrt{5}-2) \cos (\pi / 8)$. This gives the value $J / k T_{c} \approx 0.22165863$. Although this appears close to the value $0.2216546(10)$ coming from simulational studies [65], it is still over four standard deviations away. In [66], Fisher showed that Rosengren's form comes from a "critical polynomial". A root of such a critical polynomial delivers the critical point in the $1 \mathrm{D}$ and $2 \mathrm{D}$ cases and the hope was that one could find the corresponding polynomial in the $3 \mathrm{D}$ case, whose vanishing specifies its 
critical point. Fisher showed that Rosengren's polynomial is a poor candidate; it does not mimic the desired features of the $d=2$ model, is not unique and the resulting estimate for $T_{c}$ is not convincing.

The question of an exact solution of the $3 \mathrm{D}$ model has again come under the spotlight recently and claims to have found the exact exponents were given in Refs. $[67,68]$. Rational values for the critical exponents, including $\alpha=0$ for the specific heat have been given with suggestions of the existence of a multiplicative logarithmic correction there $[67,68]$. Such claims are controversial because they are not in agreement with very precise (and presumably accurate) approximations coming from a variety of techniques including series expansions, renormalization group, Monte Carlo simulations and experiment [69]. Additionally, although the values given in Refs. $[67,68]$ obey the standard scaling relations, as they should, a logarithmic term in the specific heat would contradict the scaling relations for logarithmic corrections [72]. The recent claims of [68] and related papers [70] were criticised in Refs. [71].

Exact studies of the Ising model in low dimensions continue apace. Boris Kastening recently presented a simplified version of Kaufman's solution and extended it to various boundary conditions $[73,74]$. Alfred Hucht exactly calculated the partition function of the square lattice Ising model on the rectangle with open boundary conditions for arbitrary system size and temperature [75]. For the three-dimensional model, Sheer El-Showk and collaborators produced a series of papers hoped to lead to a solution of the conformal field theory for describing the three dimensional Ising model at the critical temperature $[76,77]$. Their bounds are consistent with previous estimates such as from renormalization group, experiments and Monte Carlo simulations. As they say in the final sentence of their first paper: "We have not yet solved the 3D Ising model, but we have definitely cornered it" [76]. In their second paper they ask: "Could it be that the critical 3D Ising model is, after all, exactly solvable?" If not, El-Showk et al. at least have a very efficient method to solve it numerically [77].

Besides these exact results, a vast number of papers appear annually which are related to the Ising model. Indeed, through the renormalization group we now know that the validity of the Ising model and its critical exponents extends far beyond anything that could have been envisaged by Lenz or Ising in the 1920s, by Landau in the 1930s or Onsager in the 1940s. We refer to the second edition of McCoy and Wu's famous book for a discussion of the development in the Ising model since the early 1970s [78].

\section{EXPERIMENTAL ASPECTS OF THE ISING MODEL}

\section{A. Universality}

As discussed in the previous sections, a key theoretical concept of critical phenomena which occur at second order phase transitions is that of universality $[79,80]$. According to this concept, among the properties which de- scribe critical singularities in the neighborhood of a second order phase transition, some exhibit a rather robust character, which means that they do only depend on very general - essential - properties of the system under interest. Other - non-essential - characteristics are often called details in this context. Among the essential characteristics, one usually mentions space dimensionality, symmetries, range of interactions (see Section IV). The very nature of the interactions on the other hand, such as whether they are of magnetic or of electric origin, would they follow from classical or from quantum description of matter, etc, is not essential. This robustness must also be explained in deeper detail. Among the universal properties or characteristics, the critical exponents which describe the leading singularities of the thermodynamic quantities are probably the most famous ones. Certain combinations of the critical amplitudes, these numbers which appear in prefactors of the leading singularities, also are universal. All these are just pure numbers, the set of which defines a universality class. According to the universality argument, let us assume that measurements are performed on some real material which is expected to have the required symmetries to belong to a given universality class. Then, extremely strong predictions can be made for its critical properties. For example if a system is expected to fall in the 2D Ising model universality class, the critical exponent describing, let us say its spontaneous magnetization, has to be $1 / 8$. Not another number close to 0.125 , but exactly 0.125 ! And if it is not the case, then, the experiment is wrong! This is the incredibly strong predicting power of the theory of critical phenomena. Of course, our statement that the experiment would be wrong is exaggerated, and reality does not always simply fits mathematical symmetries. Proving that a given material exhibits the correct symmetries may be very challenging, but there are many experimental situations in which the expected universal properties can be measured. Thanks to universality again, although the real material is often only approximately a representative of a given universality class, deviations from the correct symmetry may appear to be non-essential. We will illustrate below the concept of universality with experiments performed on real materials which belong to the Ising model universality class, either in 2D or in 3D. There exist plenty of successful experiments and we will essentially describe two of them which we consider particularly outstanding.

\section{B. Ising model behaviour in rare-earth materials}

The conditions to be fulfilled by real materials in order to be quantitatively described by the Ising model are compelling. Magnetic materials offer obvious candidates which are known to exhibit a rich variety of phase transitions, with transition temperatures ranging from very low to very high, as a result of the wide range of variations of the magnetic interactions. We first have to understand the behaviour of single magnetic ions in a crystalline environment and two preliminary conditions 
are required. First the ground state has to be a doublet separated energetically from the excited states by a gap which is much larger than $k_{B} T_{c}$, where $T_{c}$ is the transition temperature. Second, in order to keep the ground state degeneracy, the operators involved in the spin-spin interactions should all have vanishing matrix elements between the two Ising states. For example, the exchange interaction $-J \mathbf{s}_{i} \cdot \mathbf{s}_{j}$ transforms like a vector and as such, obeys the selection rules $\Delta m=0, \pm 1$ where $m$ is the angular momentum projection. Both conditions are often satisfied in compounds based on rare-earth and one of the first materials which has been studied in this context is the dysprosium ethyl sulfate, $\mathrm{Dy}\left(\mathrm{C}_{2} \mathrm{H}_{5} \mathrm{SO}_{4}\right)_{3} .9 \mathrm{H}_{2} \mathrm{O}$ [81-83] with a doublet ground state in the angular momentum state $|15 / 2, \pm 9 / 2\rangle$ with weak superposition of $|15 / 2, \mp 3 / 2\rangle$ and $|15 / 2, \mp 15 / 2\rangle$. Local anisotropy axes are furthermore parallel to the hexagonal crystal axis. The system is thus well described by a microscopic Hamiltonian

$$
H=\frac{1}{2} \sum_{i, j} K_{i j} \sigma_{z i} \sigma_{z j}
$$

where the sum extends over the pairs of spins $i$ and $j$, presumably decaying with the distance among them. There is no quantitative theory which would allow for a direct calculation of the interaction strength $K_{i j}$, and these parameters have to be obtained by the comparison between experimental results and theoretical predictions of thermodynamic quantities in regions of the parameters where such theories are asymptotically exact, i.e. when $T$ is either far above $T_{c}$ or far below $T_{c}$. This is for example the case when the susceptibility is expanded in the moments of the spin-spin interaction. Earlier studies then compared experimental results with approximate theories: molecular field models, cluster models, series expansions, etc, which, having no adjustable parameters, were quite conclusive except maybe in the very neighborhood of the transition.

Long power series expansions started to become available in the 1960's and allowed for quantitative agreement in a wider range of parameters, leading to the experimental determination of the 3D Ising model critical exponents. The difficulty with fits to critical point predictions is that the asymptotic range is generally very narrow and limited by rounding effects which broaden the singularities. These effects are described by corrections to scaling, e.g.

$$
C(T, H=0)=A_{ \pm}|t|^{-\alpha_{ \pm}}\left(1+D_{ \pm}|t|^{\omega_{ \pm}}\right)+B_{ \pm}
$$

with $t=\left(T-T_{c}\right) / T_{c}$, which require adjusting the experimental data to non-linear fitting with in our example not less than 11 parameters (if we do not impose theoretical requirements like $\alpha_{+}=\alpha_{-}$, etc)!

Similar studies then extended over half a century (extensive early references can be found in the reviews [84-86]). Many experimental problems were challenging. For example the presence of dipole-dipole interactions lead to demagnetizing factors which result in a sampleshape dependence, or to long-range interactions which modify the upper critical dimension above which mean field exponents become exact (the system under consideration is no longer in the Ising universality class). Other phenomena which can be encountered experimentally are field induced phase transitions (experimentally a non-zero magnetic field is applied to promote one spin orientation and single domain samples), frustration (due to competing local anisotropy axes), disorder (associated with the presence of vacancies or defects). In spite of all these shortcomings, which lead to rather large differences between the model Hamiltonian and the experimental situation, the agreement between theory and experiment is relatively unaffected, and this is a result of the extreme robustness of universal quantities in the theory of critical phenomena in general, and of the Ising model in particular, which is spectacularly exemplified below.

\section{A beautiful test of $2 \mathrm{D}$ Ising model universality}

Two-dimensional phase transitions may occur in very different physical systems. The study of two-dimensional matter was initiated in the 19th century with molecular films of non-soluble molecules on liquid surfaces, and later with physisorbed atoms on solid surfaces. During decades however, investigators were not able to observe experimentally the characteristics of two-dimensional transitions, mainly because of the heterogeneity of the adsorbents with multiple exposed crystal surfaces, defects, or chemisorbed contaminants. In the 1970s, lamellar solids, like graphite appeared well suited to such studies and nowadays, 2D adsorbed matter is the subject of numerous works [87]. Reconstruction at crystal surfaces also offers natural candidates to test experimentally two-dimensional universality classes, e.g. the continuous structural transition of $\mathrm{Au}(110)$ investigated through LEED experiments, which appears to follow Onsager's solution of the two-dimensional Ising model [88].

But we will report here on the wonderful experiments performed by C. H. Back, Ch. Würsch, A. Vateriaus, U. Ramsperger, U. Maier and D. Pescia [89], where confirmation of a scaling behaviour belonging to the 2D Ising model universality class was shown to be satisfied over 18 and 32 orders of magnitude in terms of the properly scaled variables!

The experimental system consists in an atomic layer of ferromagnetic iron deposited on a non-magnetic substrate made of single-crystal W(110) surface, and provides a typical two-dimensional system. The epitaxial growth guarantees crystalline order and avoids disorder (as much as possible). The fact that the system obeys the Ising symmetry (i.e. typically \pm 1 magnetization in normalized units) was confirmed by the square shape of the hysteresis loop, measured by the magnetooptic Kerr effect. It also confirms the absence of domains in the sample. In the vicinity of the critical point $t=\left(T / T_{c}-1\right)=0, H=0$, the temperature dependence of the spontaneous magnetization $M(t, H=0)$, the critical isotherm $M(t=0, H)$ and the zero-field susceptibilty $\chi(t, H=0)$ were measured, leading to the correspond- 
ing critical exponents through $M(t, H=0) \sim(-t)^{\beta}$, $M(t=0, H) \sim|H|^{1 / \delta}$ and $\chi(t, H=0) \sim|t|^{-\gamma}$, $\beta=0.13 \pm 0.02, \delta=14 \pm 5$ and $\gamma=1.74 \pm 0.05$. This is a typical illustration of the possible experimental accuracy which can be achieved, where 2D Ising expected exponents are $\beta=1 / 8, \delta=15$ and $\gamma=7 / 4$. Even more impressive is the determination of the susceptibility amplitudes $\Gamma_{ \pm}$(via expressions $\chi(t, H=0) \sim \Gamma_{ \pm}|t|^{-\gamma}$ ) and their ratio $\Gamma_{+} / \Gamma_{-}=40 \pm 10$, where theory says that $\Gamma_{+} / \Gamma_{-}=37.7$.

Testing universality can be pushed further. The scaling hypothesis [57, 90-93] states that thermodynamic functions can be written in the vicinity of the critical point as generalized homogenous functions, e.g.

$$
M(t, H)=b^{-\beta / \nu} \tilde{m}\left(b^{1 / \nu} t, b^{\beta \delta / \nu} H\right)
$$

where $b$ is an arbitrary scaling factor. Fixing $b=1 / M^{\nu / \beta}$ above yields $\tilde{m}\left(t / M^{1 / \beta}, H / M^{\delta}\right)=1$, which then allows to write the parametric equation of state in terms of rescaled variables,

$$
H / M^{\delta}=f\left(t / M^{1 / \beta}\right)
$$

The experiment of Back et al., see Fig. 8, reported this rescaled equation of state fitted to theoretical results [94] over 18 orders of magnitude in the variable $t / M^{1 / \beta}$ and almost 32 orders of magnitude in $H / M^{\delta}$ !

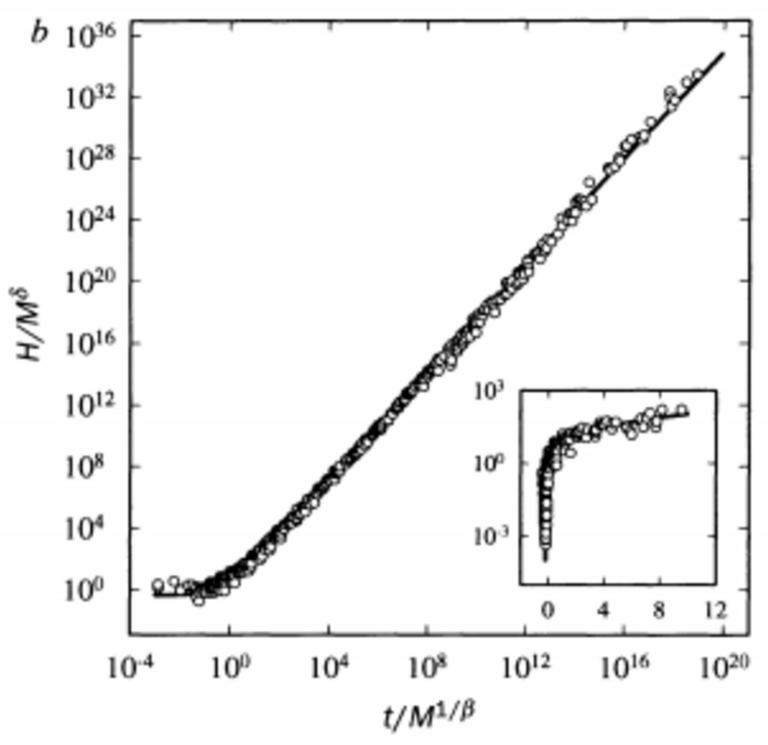

Fig. 8. Universal plot from [89].

This might be considered as a real achievement and an incredible success of the theoretical prediction, which even raises the opposite question: how is it that all experimental imperfections, inhomogeneities which break translational symmetry, non-localized local magnetic moments (Fe is a broad-band metallic ferromagnet when the Ising Hamiltonian is written in terms of localized ones), non-perfect uniaxial local symmetry and possibly other sources of discrepancy do not destroy the 2D Ising model universality class. Although there cannot be a simple answer to such questions, some of these effects are understood within the frame of universality. Disorder for example can be shown not to change (up to logarithmic corrections) the 2D Ising model universality class [95], and the experimental evidences reported in [89] support a scenario where all imperfections mentioned eventually prove to be non-essential (we say irrelevant in the renormalization group language [96,97]).

\section{SIMPLE MODEL OF COMPLEX SYSTEMS}

But let your communication be, Yea, yea; Nay, nay: for whatsoever is more than these cometh of evil.

(Matthew 5:37)

It is stated sometimes, that although the Ising model is not realistic, its success to a large extent is caused by the fact that it allows analytic treatment (see e.g. [2] and discussions therein). In this sense, it belongs to the "narrow class of models which are balanced (precariously!) between realism and solubility" [99]. This is certainly true, but our belief is that there is another - even more important - reason for the tremendous success of the Ising model. The simplicity of the model not only enables its analytic treatment, it also singles out an essential feature: binarity, i.e. representation of something as a pair of binary oppositions (cf. Umklappmagnets in section III). It is this feature that enables a much wider set of applications of the model. Moreover, and as we will see below, this feature has aided the exportation of very notions of physics to other fields, giving rise to science of complex systems [100]. Indeed, the model tailored by the "usual procedure of separating the phenomena till one deals with simple elementary facts" (as Ising himself noted on a different occasion in his other paper [101]) singles out the notion of binarity and enables analytic treatment. This is corroborated by the remark in [102] that such an approach in the condensed matter theory "consists of building a model of the system which is simple enough to handle, but rich enough to capture the relevant properties. These simplifications give rise, among others, to classical spin models. A paradigmatic example is the Ising model [26], originally devised to study magnetism." In turn, this enables one to apply the model in almost all fields where binarity plays a core role. Sometimes this role is not obvious from the very beginning and this is the skill of researchers to find a subtle connection between the cause and the consequence.

In the epigraph to this chapter we have chosen probably one of the oldest written references suggesting a binary opposition [98]. Indeed, binary variables (plus or minus one, up or down, filled or empty, active or passive) are ubiquitously used in describing various processes occurring in nature and in human society. Quantitative descriptions of such processes, on the one hand, allow us to apply methods developed in one field to another, and on the other hand, this triggers a search for similarities between very different phenomena and ordering them into different classes. This also fosters transfer of knowledge from one branch to another. As we will see from several 
examples given below, applications of the Ising model for quantitative descriptions and understandings of different phenomena of physical, chemical, biological, or social nature, as well as its application in humanities is based on the fundamental fact that actually the very essence of these phenomena is hidden in their statistical nature. In the so-called agent-based modeling that lies in the core of such descriptions, one considers a whole system as a set of agents (individuals in social systems; spins in magnets) that are capable of autonomous behaviour. Usually, an agent has a well-defined internal state and interacts with other agents. Allowing such agents to be in one of two possible states leads to the Ising model description.

Currently, there are numerous applications of the Ising model to explain chemical or biological phenomena. The amount of the studies and their success lead to the situation when e.g. such typically biological phenomena as the dynamics of pattern formation in neural networks $[103,104]$ or protein folding [105] became conventional and well-established fields of physics. The Ising model is being successfully used to explain properties of living organisms on all scales. Just to give some examples, on a molecular and cellular scale, it is adapted to the analysis of complex genetic models with several genetic effects and with the interaction, or epistasis, between the genes (see [106] and references therein) and serves as a framework for phase transitions in multicellular environments [107]. On the other extreme, at the scale of ecosystems, it explains how a critical transition can emerge directly from the dynamics of ecological populations [108]. In ecology, long-range synchronization of oscillations in spatial populations may elevate extinction risk. Therefore, such phenomena may signal an impending catastrophe.

The above examples of the Ising-model applications, although outside physics still concern systems that traditionally belong to natural sciences. As a next step, let us illustrate how it is applied in social sciences, where an important topic is to understand the social dynamics of a community, e.g. its transition from an initial disordered state to a configuration that displays at least partial order [5,6,109-114], see Fig. 9 as an example. Inspired by the idea to exploit binarity in social choice,
T.C. Schelling has suggested a model to describe racial segregation in cities [115]. There, in particular, special attention is paid to the analysis of the relation between individual and collective states: "But evidently analysis of 'tipping' phenomena wherever it occurs - in neighborhoods, jobs, restaurants, universities or voting blocs-and whether it involves blacks and whites, men and women, French-speaking and English-speaking, officers and enlisted men, young and old, faculty and students, or any other dichotomy, requires explicit attention to the dynamic relationship between individual behaviour and collective results" [115]. Although the phenomenon of interest in the above example is rather the phase separation and not an onset of a phase, an analogy with the Ising model is obvious but it has not been recognized in the original paper. Only later the similarities between phase separation into domains in the Ising model at $T=0$ and residential segregation in the Schelling model were recognized and the equivalent of the temperature $T$ was introduced into the Schelling model [116].

When the authors of [117] identified the binarity of the states of social agents to describe the phenomenon of strikes, the analogy with the Ising model was apparent. As Serge Galam recalls in his book: "we developed the idea of using an Ising ferromagnetic system to describe the collective state of an assembly of agents, each being in either one of two distinct individual states, that of working or striking. This produces two collective ordered states: a working state versus a striking state. The ferromagnetic coupling between agents was motivated by the social fact that people have the tendency to reproduce the leading choice of their neighbors, in particular in conflicting situations. We thus implemented the first application of the Ising model to describe the global state of a firm..." [6]. Currently, the analysis of opinion dynamics widely exploits agent-based modeling with agents being in discrete binary states. The most widely used models in this context are the voter model $[118,119]$, majority rule models [120], the Sznajd model [121,122] and other models based on a social impact theory [123] and its extensions $[125,126]$. A detailed review of these and other models may be found in [5].

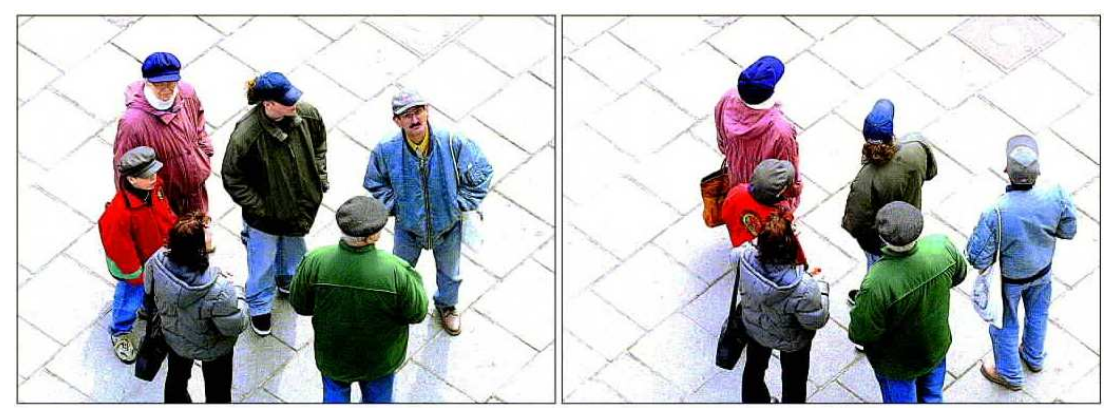

Fig. 9. People, similarly to magnets, may experience symmetry breaking. At the beginning all of them look in different directions (low order, high symmetry). Then somebody shouts from the other side and all start staring in the same direction (high order, low symmetry). And this is in spite of the fact that only one of them has heard the call: curiosity serves as an interaction between the people. (Illustration and caption is taken from the mass media article about phase transitions: Der Standard, 02.04.2002, Austria). 
Concepts of the phase transition theory, and, more specifically, the Ising model are being also actively used in the field of economics and financial markets, explaining, in particular, the statistical properties that are common to a wide range of financial assets $[127,128]$. In modeling financial markets, agents are identified with spin variables which can take specific values depending on the agent's decisions: the +1 spin as a buyer and -1 as a seller [129-135]. Considering also the case when an agent may stay inactive $(S=0)$ leads to further generalization [136-140]. Such approaches allow to study inherent features observed in the collective behaviour of financial markets: herding, bubbles or crashes, and to reproduce main statistical observations of the real-world markets such as fat-tailed distribution of returns or volatility clustering.

In Social Sciences, we can also mention elegant applications of the Ising model to Natural Language Processing, via the ability of magnetic models of statistical physics to extract the essential information contained in texts. Documents are represented as sets of interacting magnetic units (words), and a textual energy is defined as an indicator of information relevance which allows automatic abstract production, information retrieval, document classification and thematic segmentation. The compression of a sentence appears as the ground state of the chain of terms and variants are produced by thermal fluctuations [142].

In almost every example given above the Ising model was used to shed light on the behaviour of systems composed of many interacting agents, which display collective behaviour that does not follow trivially from the behaviours of the individual parts. Such systems are currently known as complex systems [141]. Their inherent features incorporate self-organization, emergence of new functionalities, extreme sensitiveness to small variations in the initial conditions, power laws governing their statistics (fat-tail behaviour) [143-145]. Their systematic study gave rise to complex system science: the field of knowledge that is actively developed and shaped nowadays. ${ }^{18}$ Usually, quantitative description of such systems is achieved by considering agents located on the nodes of a graph called complex network [147-149]. Linking between the graph nodes corresponds to the interaction between the agents under analysis. For social systems it corresponds to social interactions, for ecological systems it may reflect the predator-pray relation between species, for transportation systems it correspond to transportation links, etc. In this sense, treating the Ising model on complex networks has various applications in complex system science. Of special importance are the so-called small-world [150] and scale-free [151] networks. The former are characterized by small characteristic sizes (usually, their typical size $\ell$ logarithmically grows with number of nodes $N: \ell \sim \ln N)$. The latter are characterized by the power-law decay of the node degree distribution $P(k) \sim k^{-\lambda}$. Many important natural and man-made networks are small world and scale-free. Examples are given by the internet, world-wide web, some transportation, biological, social networks [147-149]. The properties of the Ising model on such types of networks essentially differ from its properties on $d$-dimensional lattice. The scale-free networks with slowly decaying nodedegree distribution (fat-tailed distributions with small $\lambda)$ are highly inhomogeneous. It appears that the decay exponent $\lambda$ plays a role in some sense similar to that of dimensionality $d$ : the Ising model on a scale-free network with $\lambda \leq 3$ is ordered for any finite temperature $T$ whereas it has a finite $T$ second order phase transition for $\lambda>3$. Moreover, the basic concept of universality is revised: the critical exponents attain $\lambda$-dependency in the region $3<\lambda<5$ [152-154] and the logarithmic corrections to scaling appear at $\lambda=5[72,155]$.

These and many more unusual features of the Ising model on complex networks are currently well established by different approaches (see [156] for a review) and recently revisited by the Lee-Yang-Fisher zeros analysis $[157,158]$.

There are at least two lessons one can learn from the short account given in this chapter. Indeed, exploiting the Ising archetype in the agent-based modeling of various complex systems of chemical, biological, social, economical origin gives a possibility to quantify them and to understand some of the mechanisms of their behaviour. In this sense the model enables one to single out universal common features of different systems. However, more than this: it would be too trivial to reduce the behaviour of these systems just to a single archetype no matter how powerful and general the archetype is. Along with universality in the behaviour of many-agent interacting systems, they are characterized by system-specific diversity. Subtle changes in their parameters may lead to crucial changes in their global behaviour: this is another inherent feature of complex systems. In their description, the Ising model plays a role of the main 'course', however these are the spices which make the whole dish tasty.

We have already mentioned Ising's paper [101] at the beginning of this chapter. There, discussing Goethe's approach to analysing nature he says the following: "... his approach to science was that of an artist who thought he could conceive the secrets of nature in all their complexity... He was convinced that translation into language of mathematics was distortion of reality...". Contrary to Goethe's belief, nowadays Ising-like models completed by ideas from complex system science come into play as simple models on the way to "conceive the secrets of nature in all their complexity".

\footnotetext{
${ }^{18}$ It is worth mentioning here words of Wolfgang Pauli from his letter to Herman Levin Goldschmidt (Feb. 19, 1949) [146]: "It seems to me as a philosophical layman that the task of philosophy consists in generalizing the emerging insights of current physics - that is, all its essential elements - in such a way that it can be applied to fields more general than physics. Such an achievement would, in turn, enrich the individual disciplines and prepare future developments."
} 
[1] S. G. Brush, Rev. Mod. Phys. 39 (1967) 883.

[2] M. Niss: (a) Arch. Hist. Exact Sci. 59, 267 (2005); (b) Arch. Hist. Exact Sci. 63, 243 (2009); (c) Arch. Hist. Exact Sci. 65, 625 (2011); M. Niss, Phenomena, Models and Understanding. The Lenz-Ising Model and Critical Phenomena 1920-1971. Thesis (2005); see also: C. Domb. The Critical Point A historical introduction to the modern theory of critical phenomena (Taylor \& Francis, London, 1996).

[3] S. Kobe: ${ }^{(a)}$ Phys. Bl. 51, 426 (1995); ${ }^{(b)}$ J. Stat. Phys. 88, 991 (1997) 991; ${ }^{(c)}$ Phys. Bl. 54, 917 (1998); ${ }^{(d)}$ Brazil. J. Phys. 30, 649 (2000).

[4] D. Sornette, Rep. Prog. Phys. 77, 062001 (2014).

[5] C. Castellano, S. Fortunato, V. Loreto, Rev. Mod. Phys. 81, 591 (2009).

[6] S. Galam, Sociophysics: A Physicist's Modeling of Psycho-Political Phenomena (Springer-Verlag, Berlin, 2012).

[7] S. Torquato, Phys. Biol. 8, 015017 (2011).

[8] A. Jiménez, K. F. Tiampo, A. M. Posadas, Nonlin. Processes Geophys. 14, 5 (2007).

[9] K. Vogt, A. de Campo, G. Eckel, in Proc. of the 3rd Congress of the Alps Adria Acoustics Association (Graz, Austria, September 27-28, 2007); N. Hörmann, H. Markum, W. Plessas, K. Vogt, in Proc. of the 23rd International Conference on High Energy Physics (Moscow, 2006); K. Vogt, W. Plessas, A. de Campo, C. Frauenberger, G. Eckel, in Proc. of the 13th International Conference on Auditory Display (Montreal, Canada, June 26-29, 2007).

[10] G. De las Cuevas, T. S. Cubitt, Science 351, 1180 (2016).

[11] http://www.icmp.lviv.ua/ising/

[12] G. H. Wannier, Statistical Physics (Wiley \& Sons, New York, 1966).

[13] L. P. Kadanoff, Stud. History Philos. Mod. Phys. 44, 22 (2013).

[14] P. Curie, Annal. Chim. Phys., 5, 289 (1895).

[15] P. Curie,Archives des Sciences physiques et naturelles, 3e période, tome XXVI, 13 (1891); reprinted in: Euvres de Pierre Curie (Gauthier-Villars, Paris, 1908), p. 214.

[16] N. Bohr, [originally published as Studier over Metallernes Elektrontheori, Københavns Universitet (1911)] The Doctor's Dissertation (Text and Translation), in: Early Works (1905-1911). Niels Bohr Collected Works. 1, edited by L. Rosenfeld, J. Rud Nielsen (Elsevier), p. 163.

[17] H. J. van Leeuwen, J. Phys. Radium 2, 361 (1921).

[18] W. Lenz, Phys. Z. 21, 613 (1920).

[19] P. Weiss,Comptes Rendus 143, 1136 (1906).

[20] Karin Reich, in: Mathematics meets physics. A contribution to their interaction in the 19th and the first half of the 20th century, edited by Karl-Heinz Schlote, Martina Schneider (Frankfurt am Main, 2011), p. 89.

[21] E. Ising, Beitrag zur Theorie des Ferro- und Paramagnetismus. Dissertation zur Erlangung der Dok- torwürde der Mathematisch-Naturwissenschaftlichen Fakultät der Hamburgischen (Universität vorgelegt von Ernst Ising aus Bochum, Hamburg, 1924), see: http://www.icmp.lviv.ua/ising/books.html An excerpt of the thesis "Contribution to the Theory of Ferromagnetism" translated by Jane Ising and Tom Cummings can be found on the webpage of the Bibliotheca Augustina. For a detailed discussion see [2] ${ }^{(a)}$ p. 279.

[22] W. Heisenberg, Z. Phys. 49, 619 (1928).

[23] L. Onsager, Phys. Rev. 65, 117 (1944).

[24] H. A. Kramers, G. H. Wannier, Phys. Rev. 60, 252 (1941).

[25] H. A. Kramers, G. H. Wannier, Phys. Rev. 60, 263 (1941).

[26] E. A. Ewing, Proc. Roy. Soc. 48, 342 (1890).

[27] W. Schottky, Phys. Z. 23, 448 (1922).

[28] E. Ising, Z. Physik 31, 253 (1925).

[29] A. Landé, Naturwissenschaften 11, 725 (1923).

[30] H. Kragh, Quantum Generations A History of Physics in the Twenteeth Century (Princton University Press, Princeton, 1999).

[31] Nobel lecture delivered in Stockholm December 13, 1946, in: W. Pauli. Writings on Physics and Philosophy, edited by C. P. Enz, K. von Meyenn (Springer Verlag, Berlin, 1994).

[32] A. I. Miller, 137 Jung, Pauli, and the pursuit of a scientific obsession (W. W. Norton \& Company, London, 2009).

[33] W. Pauli, Z. Phys. 31, 373 (1925) (received 2 December, 1924); Z. Phys. 31, 765 (1925) (submitted 16 January, 1925).

[34] Ch. P. Enz, No Time to be Brief (Oxford University Press, Oxford, 2002).

[35] D. Giulini, Stud. History Philos. Sci. B 39, 557 (2008).

[36] K. von Meyenn: ${ }^{(a)}$ Phys. Bl. 36, 293 (1980); ${ }^{(b)}$ Phys. Bl. 37, 13 (1981); ${ }^{(c)}$ Phys. Bl. 56, 49 (2000).

[37] M. Jacobi, Physik in unserer Zeit 30 (4), 153 (1999).

[38] (a) G. E. Uhlenbeck, S. Goudsmit, Naturwissenschaft 13, 953 (1925); ${ }^{(b)}$ Nature 117, 264 (1926).

[39] L. Hoddeson, G. Baym, M. Eckert, Crystal Maze Chapters from the History of Solid-State Physics (Oxford University Press, Oxford, 1992). W. Heisenberg, Z. Phys. 49, 619 (1928).

[40] W. Pauli, Rapports et Discussions du Sixième Conseil de Physique tenu à Bruxelles du 20 au 25 Octobre 1930 (Gautirer-Villars, Paris, 1932).

[41] E. Luijten, in: Computer Simulation Studies in Condensed-Matter Physics XII, edited by D. P. Landau, S. P. Lewis, H. B. Schüttler (Springer, Heidelberg, 2000), p. 86.

[42] E. H. Lieb, D. C. Mattis. Mathematical Physics in One Dimension: Exactly Soluble Models of Interacting Particles (Academic Press, 1966).

[43] J. C. Bonner, J. Appl. Phys. 49, 1299 (1978).

[44] R. Peierls, Proc. Camb. Phil. Soc. 32, 471 (1936); 32, 477 (1936). 
[45] D. C. Mattis, Theory of Magnetism. II. Thermodynamics and Statistical Mechanics (Springer, Berlin, 1985).

[46] L. Landau, Ukr. J. Phys. 53, 25 (2008) [English translation of the paper in Zh. Eksp. Teor. Fiz. 7, 19 (1937)].

[47] J. E. Verschaffelt, Proc. Kon. Akad. Amsterdam 2, 588 (1900).

[48] W. L. Bragg, E. J. Williams, Proc. Roy. Soc. A 145, 699 (1934); 151, 540 (1935).

[49] H. A. Bethe, Proc. Roy. Soc. A. 150, 552 (1935).

[50] P. Ehrenfest, in Proceedings of the Royal Academy, Amsterdam36, 153 (1933), (Suppl. No 75b, Commun. Kamerlingh Onnes Inst. Leiden).

[51] T. Sauer, Eur. Phys. J. Spec. Top. 226, 539 (2017).

[52] S. M. Bhattacharjee, A. Khare, Curr. Sci. 69, 816 (1995); Erratum, ibid. 71, 493 (1996).

[53] B. Kaufman, Phys. Rev. 76, 1232 (1949).

[54] B. Kaufman, L. Onsager, Phys. Rev. 76, 1244 (1949).

[55] C.N. Yang, Phys. Rev. 85, 808 (1952).

[56] R. J. Baxter, J. Stat. Phys. 145, 518 (2011); 149, 1164 (2012).

[57] A. Z. Patashinskii, V. L. Pokrovskii, Zh. Eksp. Teor. Fiz. 50, 439 (1966) [Sov. Phys. JETP 23, 292 (1966)].

[58] A. B. Zamolodchikov, Int. J. Mod. Phys. A 4, 4235 (1989).

[59] M. Henkel, Conformal Invariance and Critical Phenomena (Springer, Berlin, 1999).

[60] S. G. Brush, Statistical Physics and the Atomic Theory of Matter (Princeton University Press, Princeton, 1983).

[61] M.E. Fisher, Rev. Mod. Phys. 70, 653 (1998); Int. J. Mod. Phys. B 29, 1530006 (2015) .

[62] M. Maddox, Changements de Phase. Comptes Rendus de la deuxiéme Reunion Annuelle tenue en commun avec la commission de Thermodynamique de l'Union Internationale de Physique (Paris, Société de Chimie Physique, 1952), p. 226.

[63] F. J. Murray, Ann. Math. 55, 250 (1952).

[64] A. Rosengren, J. Phys. A: Math. Gen. 19, 1709 (1986).

[65] H. W. J. Blöte, E. Luijten, J. R. Heringa, J. Phys. A: Math. Gen. 28, 6289 (1995).

[66] M. E. Fisher, J. Phys. A: Math. Gen. 28, 6323 (1995).

[67] J. Kaupuzs, Ann. Phys. 10, 299 (2001).

[68] Z. D. Zhang, Phil. Mag. 87, 5309 (2007).

[69] A. Pelissetto, E. Vicari, Phys. Rep. 368, 549 (2002).

[70] N. H. March, Phys. Lett. A 379, 820 (2015).

[71] M. E. Fisher, J. H. H. Perk, Phys. Lett. A 380, 1339 (2016).

[72] R. Kenna, in Order, Disorder and Criticality. Vol 3, edited by Yu. Holovatch (World Scientific, Singapore, 2013), p. 1.

[73] B. Kastening, Phys. Rev. E 64, 066106 (2001).

[74] B. Kastening, Phys. Rev. E 66, 057103 (2002).

[75] A. Hucht, J. Phys. A: Math. Theor. 50, 065201 (2017).

[76] S. El-Showk, M. F. Paulos, D. Poland, S. Rychkov, D. Simmons-Duffin, A. Vichi, Phys. Rev. D 86, 025022 (2012).

[77] S. El-Showk, M. F. Paulos, D. Poland, S. Rychkov, D. Simmons-Duffin, A. Vichi, J. Stat. Phys. 157, 869 (2014).

[78] B. M. McCoy, T. T. Wu, The Two-Dimensional Ising Model, 2nd Edition (Dover Publications, New York, 2014)

[79] M. E. Fisher, Rep. Prog. Phys. 30, 615 (1967).

[80] L. P. Kadanoff et al., Rev. Mod. Phys. 39, 395 (1967).
[81] A. H. Cooke, D. T. Edmonds, F. R. McKim, W. P. Wolf, Proc. R. Soc. Lond. A 252, 246 (1959).

[82] A. H. Cooke, D. T. Edmonds, C. B. P. Finn, W. P. Wolf, Proc. R. Soc. A 306, 313 (1968).

[83] A. H. Cooke, D. T. Edmonds, C. B. P. Finn, W. P. Wolf, Proc. R. Soc. A 306, 335 (1968).

[84] L. J. de Jongh, A. R. Miedema, Adv. Phys. 23, 1 (1973).

[85] E. Stryjewski, N. Giordano, Adv. Phys. 26, 487 (1977).

[86] W. P. Wolff, J. Phys. 30, 794 (2000).

[87] A. Thomy, X. Duval, J. Régnier, Surf. Sc. Rep. 1, 1 (1981).

[88] J. C. Campuzano, M. S. Foster, G. Jennings, R. F. Willis, W. Unertl, Phys. Rev. Lett. 54, 2684 (1985).

[89] C. H. Back, Ch. Würsch, A. Vateriaus, U. Ramsperger, U. Maier, D. Pescia, Nature 378, 597 (1995).

[90] B. Widom, J. Chem. Phys. 43, 3898 (1965).

[91] C. Domb, D. L. Hunter, Proc. Phys. Soc. 86, 1147 (1965).

[92] L. P. Kadanoff, Physics 2, 263 (1966).

[93] A. Z. Patashinskii, V. L. Pokrovskii, Fluctuation Theory of Phase Transitions (Pergamon Press, Oxford, 1979).

[94] D. S. Gaunt, C. Domb, J. Phys. C 3, 1442 (1970).

[95] A.B. Harris, J. Phys. C 7, 1671 (1974).

[96] S. K. Ma, Modern Theory of Critical Phenomena (Westview, New-York, 1976).

[97] K. G. Kenneth, J. B. Kogut, Phys. Rep. 12,75 (1974).

[98] D. Stauffer, Physica A 285, 121 (2000).

[99] M. Kac, in Critical Phenomena in Alloys, Magnets and Superconductors [Battelle Institute Materials Science Colloquia, Geneva and Gstaad, September, 1970], edited by R. E. Mills, E. Ascher, R. I. Jaffee (McGraw-Hill, New York, 1971), p. 23.

[100] Yu. Holovatch, R. Kenna, S. Thurner, Eur. J. Phys. 38, 023002 (2017).

[101] E. Ising, Am. J. Phys. 18, 235 (1950).

[102] Gemma De las Cuevas, J. Phys. B 46, 243001 (2013).

[103] R. Rojas, Neural Networks - A Systematic Introduction (Springer-Verlag, Berlin, 1996).

[104] H. G. Schaap, Ising models and neural networks. Thesis. Gronigen (Universal Press - Science Publishers / Veenendaal, The Netherlands. 2005).

[105] V. Muñoz, Curr. Opin. Struct. Biol. 11, 212 (2001).

[106] J. Majewski, H. Li, J. Ott, Am. J. Human Gen. 9, 853 (2001).

[107] M. Weber, J. Buceta, J. R. Soc. Interface 13, 20151092 (2016).

[108] A. E. Noble, J. Machta, A. Hastings, Nature Commun. 6, 6664 (2015).

[109] S. N. Durlauf, Proc. Natl. Acad. Sci. USA 96, 10582 (1999).

[110] D. Stauffer, Physica A 336, 1 (2004).

[111] D. Stauffer, S. Solomon, preprint arXiv:0801.0121 (2008).

[112] S. Galam, preprint arXiv:0803.1800 (2008).

[113] P. Ball, Phys. World 16(10), 29 (2003).

[114] P. Ball, Criticall Mass. How One Thing Leads to Another (Heinemann/Farrar, Straus \& Giroux, 2004).

[115] T. C. Schelling, J. Math. Sociol. 1, 143 (1971).

[116] D. Stauffer, S. Solomon, Eur. Phys. J. B 57, 473 (2007).

[117] S. Galam, Y. Gefen, Y. Shapir, J. Math. Sociol. 9, 1 (1982).

[118] P. Clifford, A. Sudbury, Biometrika 60, 581 (1973).

[119] R. Holley, T. Liggett, Ann. Probab. 3, 643 (1975). 
[120] S. Galam, Eur. Phys. J. B 25, 403 (2002).

[121] K. Sznajd-Weron, J. Sznajd, Int. J. Mod. Phys. C 11, 1157 (2000).

[122] K. Sznajd-Weron, Acta Phys. Pol. B 36, 2537 (2005).

[123] B. Latané, Am. Psychol. 36, 343 (1981).

[124] A. Nowak, J. Szamrej, B. Latané, Psychol. Rev. 97362 (1990).

[125] F. Schweitzer, J. A. Hołyst, Eur. Phys. J. B 15, 723 (2000).

[126] F. Schweitzer, Brownian Agents and Active Particles (Springer-Verlag, Berlin, 2003).

[127] R. N. Mantegna, H. E. Stanley, Introduction to Econophysics (Cambridge University Press, Cambridge, UK, 1999).

[128] J.-P. Bouchaud, M. Potters, Theory of Financial Risks (Cambridge University Press, Cambridge, UK, 2000).

[129] S. Bornholdt, Int. J. Mod. Phys. C 12, 667 (2001).

[130] T. Kaizoji, Physica A 287, 493 (2000).

[131] T. Kaizoji, S. Bornholdt, Y. Fujiwar, Physica A 316, 441 (2002)

[132] A. Krawiecki, J.A. Hołyst, D. Helbing, Phys. Rev. Lett. 89, $158701(2002)$

[133] W.-X. Zhou, D. Sornette, Eur. Phys. J. B 55, 175 (2007).

[134] D. Sornette, W.-X. Zhou, Physica A 370, 704 (2006).

[135] P. Dvořák, From Microscopic Rules to Macroscopic Phenomena: Ising Model in Finance, unpublished bachelor thesis (Charles University in Prague, 2012).

[136] G. Iori, Int. J. Modern Phys. C 10, 1149 (1999).

[137] T. Takaishi, Int. J. Mod. Phys. C 16, 1311 (2005).

[138] A.-H. Sato, Physica A 382, 258 (2007).

[139] P. Sieczka, J. A. Hołyst, Acta Phys. Pol. A 114, 525 (2008).

[140] M. Denys, T. Gubiec, R. Kutner, Acta Phys. Pol. A 123, 513 (2013).

[141] See e.g.: P. F. Henshaw, M. McGinley, C. M. Hogan, Complex Systems, in: Encyclopedia of Earth, edited by J. Cutler Cleveland (Washington, D.C., Environmental Information Coalition, National Council for Sci- ence and the Environment); B. J. Caldwell, Cahiers de d'épistémologie 292, 23 (2003); 43 Visions for Complexity, edited by S. Thurner (World Scientific, Singapore, 2017).

[142] S. Fernandez Sabidom, Exploratory applications of spin models in Natural Language Processing, https://tel. archives-ouvertes.fr/tel-00412369 (2009).

[143] M. Mitzenmacher, Internet Math. 1, 226 (2004).

[144] M. E. J. Newman, Contemp. Phys. 46, 323 (2005).

[145] M. V. Simkin, V. P. Roychowdhury, Phys. Rep. 502, 1 (2011).

[146] K. von Meyenn, in Recasting Reality. Wolfgang Pauli's Philosophical Ideas and Contemporary Science, edited by H. Atmanspacher, H. Primas (Springer, Berlin, 2009).

[147] R. Albert, A.-L. Barabási, Rev. Mod. Phys. 74, 47 (2002).

[148] S. N. Dorogovtsev, J. F. F. Mendes, Evolution of Networks (Oxford University Press, Oxford, 2003).

[149] M. Newman, A.-L. Barabási, D. J. Watts, The Structure and Dynamics of Networks (Princeton University Press, 2006).

[150] D. J. Watts, S. H. Strogatz, Nature 393, 440 (1998).

[151] A. Barabási, R. Albert, Science 286, 509 (1999)

[152] M. Leone, A. Vázquez, A. Vespignani, R. Zecchina, Eur. Phys. J. B 28, 191 (2002).

[153] S. N. Dorogovtsev, A. V. Goltsev, J. F. F. Mendes, Phys. Rev. E 66, 016104 (2002).

[154] C. von Ferber, R. Folk, Yu. Holovatch, R. Kenna, V. Palchykov, Phys. Rev. E 83, 061114 (2011).

[155] V. Palchykov, C. von Ferber, R. Folk, Yu. Holovatch, R. Kenna, Phys. Rev. E 82, 011145 (2010).

[156] S. N. Dorogovtsev, A. V. Goltsev, J. F. F. Mendes, Rev. Mod. Phys. 80, 1275 (2008).

[157] M. Krasnytska, B. Berche, Yu. Holovatch, R. Kenna, Eur. Phys. Lett. 111, 60009 (2015).

[158] M. Krasnytska, B. Berche, Yu. Holovatch, R. Kenna, J. Phys. A 49, 135001 (2016).

\title{
ДОЛЯ ЕРНСТА ІЗІНГА І ДОЛЯ ЙОГО МОДЕЛІ
}

\author{
Т. Ізінг ${ }^{1}$, Р. Фольк ${ }^{2}$, Р. Кенна ${ }^{3,1}$, Б. Берш ${ }^{4,1}$, Ю. Головач ${ }^{5,1}$ \\ ${ }^{1} \mathbb{L}^{4}$ співпрачя $i$ Докторсъкий коледж статистичної фізики складних систем \\ Ляйпииґ-Лотаринґія-Львів-Ковентрі \\ ${ }^{2}$ Інститут теоретичної фізики, Університет Йогана Кеплера, Ліни, А-4040, Австрія \\ ${ }^{3}$ Дослідниький центр прикладної математики, Університет Ковентрі, CV1 5FB, Англія \\ ${ }^{4}$ Група статистичної фізики, лабораторія теоретичної фізики та хімї̈, \\ Університет Лотарин'їі, F-54506 Нансі, Франція \\ ${ }^{5}$ Інститут фізики конденсованих систем НАН Украӥни, 79011, Лъвів, Україна
}

У цій статті з нагоди 20-річчя "Ізінгівських читань" у Львові (Україна) ми подаємо власні роздуми про модель феромагнетизму, яку в 1920 році запропонував Вільгельм Ленц, а в 1924 році розв'язав в одновимірному випадку його аспірант Ернст Ізінг. Ця робота Ленца й Ізінга ознаменувала початок наукового напрямку, який за останні майже 100 років досягнув неабиякого успіху в описі колективної поведінки широкого кола об'єктів фізичної й нефізичної природи. Широта застосування моделі Ізінга відображається в різноманітті лекцій, представлених у межах "Ізінгівських читань" за останні два десятиліття, але вимагає, щоб ми обмежилися лише вузькою сферою тем. Стаття розпочинається зі спогадів Томаса Ізінга (сина Ернста). Відтак ми обговорюємо історію моделі, деякі точні результати, експериментальні реалізації та їі застосування в інших галузях. 